Board of Governors of the Federal Reserve System

International Finance Discussion Papers

Number 1313

March 2021

\title{
Back to the Present: Learning about the Euro Area through a Now-casting Model
}

Danilo Cascaldi-Garcia, Thiago RT Ferreira, Domenico Giannone, Michele Modugno

Please cite this paper as:

Cascaldi-Garcia, Danilo, Thiago RT Ferreira, Domenico Giannone, and Michele Modugno (2021). "Back to the Present: Learning about the Euro Area through a Now-casting Model," International Finance Discussion Papers 1313. Washington: Board of Governors of the Federal Reserve System, https://doi.org/10.17016/IFDP.2021.1313.

NOTE: International Finance Discussion Papers (IFDPs) are preliminary materials circulated to stimulate discussion and critical comment. The analysis and conclusions set forth are those of the authors and do not indicate concurrence by other members of the research staff or the Board of Governors. References in publications to the International Finance Discussion Papers Series (other than acknowledgement) should be cleared with the author(s) to protect the tentative character of these papers. Recent IFDPs are available on the Web at www.federalreserve.gov/pubs/ifdp/. This paper can be downloaded without charge from the Social Science Research Network electronic library at www.ssrn.com. 


\title{
Back to the Present: Learning about the Euro Area through a Now-casting Model ${ }^{*}$
}

\author{
Danilo Cascaldi-Garcia ${ }^{\dagger}$ \\ Federal Reserve Board \\ Domenico Giannone ${ }^{\S}$
}

Amazon.com

\author{
Thiago R.T. Ferreira ${ }^{\ddagger}$ \\ Federal Reserve Board \\ Michele Modugno \\ Federal Reserve Board
}

March 18, 2021

\begin{abstract}
We build a model for simultaneously now-casting economic conditions in the euro area and its three largest member countries - Germany, France, and Italy. The model formalizes how market participants and policymakers monitor the euro area by incorporating all market moving indicators in real time. We find that area-wide and country-specific data provide informative signals to now-cast the economic conditions in the euro area and member countries. The model provides accurate predictions of economic conditions in real time over a period that covers the past three recessions.
\end{abstract}

Keywords: Now-casting, euro area, dynamic factor models JEL codes: C33, C53, E37

*We thank Giovanni Caggiano, Todd Clark, Neil R. Ericsson, Laurent Ferrara, Ana Galvao, Andrea de Michelis, Joaquín Garcia-Cabo, Michael Owyang, John Rogers, Mirco Rubin, Tatevik Sekhposyan, Dalibor Stevanovic, Till Strohsal, Benjamin Wong, and the participants of the Economic Forecasting in Times of COVID-19 Virtual Conference, Federal Reserve Board Workshop, Society for Nonlinear Dynamics and Econometrics Symposium (SNDE), Real-Time Data Analysis, Methods and Applications Conference, IWH-CIREQ-GW Macroeconometric Workshop: Forecasting and Uncertainty, International Symposium on Forecasting, Computation and Financial Econometrics Conference, Monash University Seminar for comments and suggestions. Caitlin Dutta, Chazz Edington, Tyler Powell, and Nicolas Savignon provided excellent research assistance. Giannone's contribution to the paper was completed prior to the author joining Amazon. This publication and its contents are not related to Amazon and do not reflect the position of the company and its subsidiaries. The views expressed in this paper are solely the responsibility of the authors and should not be interpreted as reflecting the view of the Board of Governors of the Federal Reserve System or of any other person associated with the Federal Reserve System.

${ }^{\dagger}$ Federal Reserve Board, International Finance Division, Washington DC 20551, USA; E-mail address: danilo.cascaldi-garcia@frb.gov.

${ }^{\ddagger}$ Federal Reserve Board, International Finance Division, Washington DC 20551, USA; E-mail address: thiago.r.teixeiraferreira@frb.gov.

$\S$ Amazon.com, USA; E-mail address: dgiannon2@gmail.com.

ॠFederal Reserve Board, Financial Stability Division, Washington DC 20551, USA; E-mail address: michele.modugno@frb.gov. 


\section{Introduction}

The most comprehensive indicator of economic activity - gross domestic product (GDP) is typically measured at a quarterly frequency and released with a substantial delay 1 However, economists are still left with the arduous task of monitoring the economy accurately and in a timely manner. In the euro area, this task is particularly challenging for two reasons documented in this paper. First, economists follow a multi-country approach: not only market participants track macroeconomic indicators about both the euro-area aggregate and its largest countries, but also policymakers build euro-area forecasts from projections for individual countries $:^{2}$ Second, hard data are released with a substantial delay compared to other economies. Thus, market participants closely track soft data, such as confidence surveys, that provide timely snapshots about economic activity.

We then propose an econometric framework that formalizes how market participants and policymakers monitor euro-area economic conditions. Our model simultaneously now-casts the economic activity of the euro-area aggregate and its three largest member countries-Germany, France, and Italy. Using this multi-country model, we show that country-specific data are important to now-cast the euro-area aggregate GDP, and viceversa. Indeed, we find that data releases from a specific country lead to sizable GDP nowcasting revisions for not only that country, but also for other euro-area countries and the region aggregate. Similarly, data releases from the region aggregate lead to sizable GDP now-casting revisions for the countries. Our model also heavily relies on soft data, making them particularly important for now-casting the euro area and its major countries. We find that soft data releases lead to sizable GDP now-casting revisions, especially in the weeks leading to the start of the quarter.

To illustrate the reason why now-casting economic activity is an arduous task, we relive the eve of the European sovereign debt crisis using our now-casting model (Figure 1). Specifically, we focus on now-casting the euro-area 2011Q3 GDP growth because it

\footnotetext{
${ }^{1}$ For example, in the euro area and the United States, GDP is currently first released about 30 days after the end of the reference quarter. However, until 2015, the euro-area GDP was first released about 45 days after the end of the reference quarter.

${ }^{2}$ For instance, see "A Guide to the Eurosystem/ECB Staff Macroeconomic Projection Exercises" (2016).
} 
Figure 1 Euro-Area GDP Growth on the Eve of its Sovereign Debt Crisis

\section{Evolution of Estimates of Euro-Area Real GDP Growth in 2011Q3 Decomposed by Country}

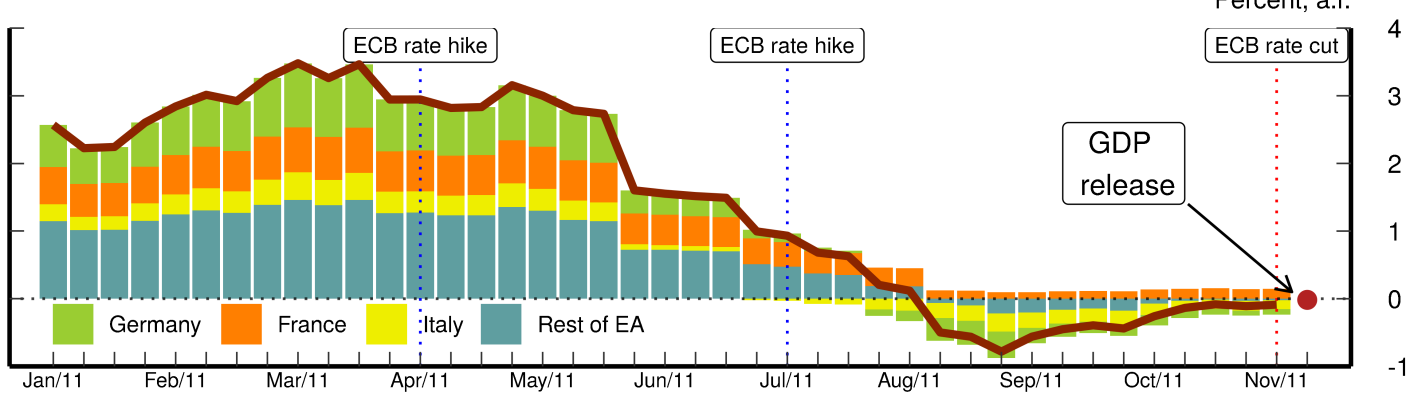

Decomposition of Now-cast Revisions by Country Percentage points, a.r.

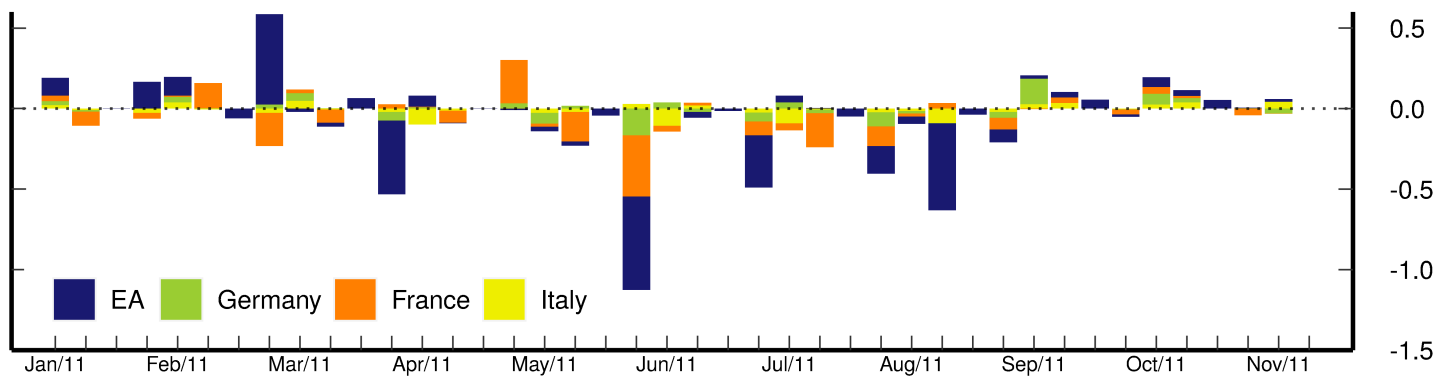

Decomposition of Now-cast Revisions by Data Percentage points, a.r.

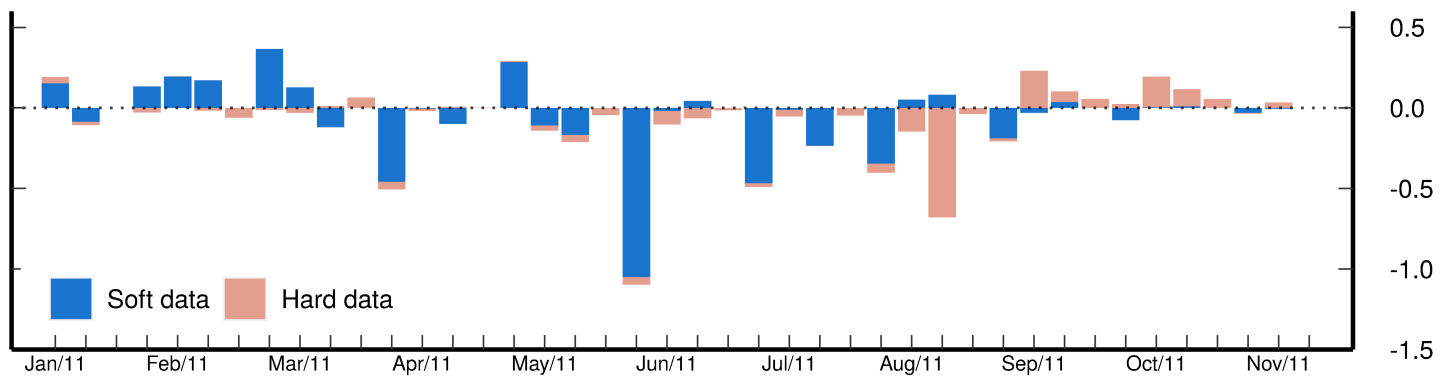

Note: Top panel presents weekly out-of-sample forecasts from our now-casting model. Blue dashed vertical lines indicate increases in policy interest rates by the European Central Bank (ECB). Red dashed vertical line indicates the November cut of the ECB's policy rates. Red dot in top panel represents the euro-area quarterly GDP growth of 2011Q3. Middle panel presents the decomposition of the model forecast revisions by the country of origin of the data, whereas the bottom panel presents revisions by hard/soft data. Revisions due to estimation update are not shown. More details in Sections 3 and 4.

was the start of the recession that followed ${ }^{3}$ Starting in March 2011, the model estimates a sharp decline in GDP growth in the euro area that was also pervasive across member countries (top panel). The contraction was so sudden that the ECB took many months to acknowledge it. Indeed, the ECB increased its interest rates twice, in April and July (blue vertical lines), still emphasizing the inflation outlook. With later data reinforcing

\footnotetext{
${ }^{3}$ We use the classification from the Centre for Economic Policy Research (CEPR).
} 
the weak GDP outlook, the ECB decreased its interest rates in November (red vertical line), right before the release of the GDP growth for 2011Q3 (red dot).

Figure 1 also illustrates how country-specific data is important to now-cast euroarea aggregate GDP, and vice-versa (middle panel). When we decompose weekly nowcasting revisions of euro-area GDP growth between those from aggregate (blue bars) and country-specific data, the latter lead to sizable revisions to GDP growth. It should not be surprising that economists simultaneously monitor data of the euro area and its major countries. Business cycle fluctuations of these economies are well synchronized (e.g., Giannone, Lenza, and Reichlin, 2010) and, hence, news about individual economies may carry important signals about other economies and the whole euro area. However, scholars have focused on single-economy now-casting models for the euro-area aggregate and its member countries and never considered a joint multi-country model. Also for the United States, the monitoring of regional information has also been given little attention. The Bureau of Economic Analysis only started publishing quarterly GDP for U.S. states in December 2015, with a larger delay than the aggregate figures, and Bloomberg relevance indexes are not available for these statewide releases.

Turning to the importance of soft data for now-casting the euro area, we find that this result arises because these data are both timely and intrinsically informative about GDP growth. Using our model, we decompose weekly now-casting revisions of GDP growth as originated from either soft or hard data. We estimate that releases of soft data typically lead to much larger now-casting revisions than those from hard data. However, the importance of soft data may depend not only on their intrinsic relationship with GDP growth, but also on the timeliness of their release (e.g., Giannone, Reichlin, and Small, 2006 and Gilbert, Scotti, Strasser, and Vega, 2017). Thus, we build a counterfactual dataset in which the release of hard data is anticipated for a schedule similar to the United States. Still, we continue to find that soft data lead to the majority of nowcasting revisions of GDP in this counterfactual calendar schedule. The lower panel of Figure 1 exemplifies these results in the eve of the European Sovereign Crisis: using our model, the timely soft data releases from June to August of 2011 lead to sizable 
downward revisions (blue bars) in the estimates for 2011Q3 GDP growth, while hard data lead to small revisions (pink bars) that mostly reinforce the previously conveyed economic deterioration.

Finally, we show that our multi-country now-casting model produces accurate predictions for the euro area and its three major countries during their past three recessions. These results come from three key features of our framework. First, it uses a large set of market-moving indicators for the euro area and its three largest economies, totaling 58 data series. We can then interpret the importance of these releases in real time for nowcasting all four economies, showing a sizable dynamic interaction between these economies and corroborating the view from practitioners that it is efficient to monitor the euro area and its major countries simultaneously. Second, our model explicitly accounts for the lead-lag relationship in the economic activity of the euro area and its main countries. This feature allows us to capture the dynamic heterogeneity of business-cycle fluctuation across countries. Third, the model handles non-synchronous data releases, exploiting the trade-off between timeliness and data quality.

The remainder of our paper is organized as follows. In Section 2, we document which euro-area data releases are tracked by market participants. In Section 3, we describe our now-casting model. In Section 4, we discuss the main now-casting results of the paper. In Section 5, we re-live the past three recessions of the euro area, showing that our model performs well in anticipating economic conditions in these periods. Section 6 concludes.

\section{The Data Flow of the Euro Area}

In this section, we document which euro-area macroeconomic indicators economists closely monitor on a daily basis, and discuss the timeliness of these indicators.

\subsection{What Euro-Area Data Do Economists Monitor?}

In the euro area, similar to the United States, every day there is a large flow of data releases revealing information about the state of the macroeconomy, and these releases 
receive major attention from economists in business, the media, and policy institutions. These economists aim at disentangling movements that are idiosyncratic to particular data releases from those signaling broad-based fluctuations in economic activity. For instance, policymakers try to anticipate economic downturns because their policy responses either take time to be negotiated (e.g., fiscal policy) or have long delays in their economic effects (e.g., monetary policy, as shown in Christiano, Eichenbaum, and Evans, 1999), while market participants build portfolios of financial assets whose performance depends on the state of the macroeconomy. Economists then carefully monitor the economy using a longstanding iterative approach: (i) using all available information, they form expectations about incoming GDP growth and soon-to-be-released key economic indicators; (ii) once a key indicator is released, they evaluate whether it was better or worse than expected and then turn to step (i) again. Indeed, when data releases differ from market participants' expectations, asset prices move in a statistical and economically significant way (e.g., Altavilla, Giannone, and Modugno, 2017).

What are the macroeconomic data releases that keep economists monitoring their computer screens during workdays? We answer this question using the Bloomberg relevance index, which calculates the percentage of Bloomberg users that set an automatic alert notifying them of a specific data release. We focus on variables with a Bloomberg relevance index above 50\%, with most of these variables also marked on the Bloomberg website as "Market Moving Indicators." ${ }^{4}$ Table 1 reports the economic indicators collected, with the corresponding Bloomberg relevance index from November, 2019, in column (7) $!^{5}$ For instance, the GDP release has an index of $90 \%$ for the euro-area aggregate, $89 \%$ for France, $80 \%$ for Germany, and $86 \%$ for Italy ${ }^{6}$ The great majority of the variables are monthly, with the only quarterly data being real GDP growth. Moreover, most variables are "headline" series, indicating that economists' data expertise leads them to view disaggregated data as not routinely important to monitor the economy, which is also

\footnotetext{
${ }^{4}$ We allow for some exceptions to this rule to include similar indicators across the different economies. For example, while euro-area and German imports are below 50\%, Italian and French imports are above. 5 McCoy, Modugno, Palazzo, and Sharpe (2020) use the relevance index to weight macroeconomic surprises in an index that explains a large portion of stock return variation over the FOMC cycle.

${ }^{6}$ On our sample, the relevance index has changed only a handful of times and for few basis points. Accordingly, we use the last available figures.
} 
consistent with the econometric evidence.7 Additionally, statistical offices and private survey owners release most of their series under a format that is stationary, and we apply additional transformations only in a few cases.

Our data set shows that economists track a large number of economic indicators, about both the euro-area aggregate and its major countries. In fact, our database has 58 indicators: 15 for Germany, 16 for France, 14 for Italy, and 13 for the euro-area aggregate; and the relevance index for many variables, such as GDP and retail sales, has similar magnitudes for the euro area and its major countries 8 This multi-country aspect of our data set signals that economists internalize that key euro-area aggregate economic variables are constructed from country-specific data, and policymakers build their forecasts by aggregating those for euro-area economies. For example, Eurostat builds the flash estimate of the euro-area GDP by aggregating its members' GDP data, instead of collecting data directly at the aggregate level, while the ECB and the European Commission follow procedures under which their forecasts for the eurozone aggregate those from individual countries.$^{9}$ These methodologies point to the importance of simultaneously tracking data from both the euro area and its major countries not only to understand regional developments, but also to forecast them. Importantly, the multi-country approach for the euro area stands in stark contrast with the one used by economists monitoring U.S. data, where state-specific counterparts of market-moving aggregate data, such as GDP, consumption and employment, are not closely followed by market participants and are published with either long delays, short historical series, or annual frequency. ${ }^{10}$

Our data set also shows that economists track variables representing many different

\footnotetext{
${ }^{7}$ For more details, see Bańbura and Modugno (2014), Bańbura and Modugno (2010), Banbura, Giannone, and Reichlin (2011), and Bańbura, Giannone, and Reichlin (2010).

${ }^{8}$ For variables about the whole euro-area economy, we use variables aggregating the 19 countries that adopted the euro as their single currency. In a few exceptions, euro-area variables are not available, so we use those defined for the European Union.

${ }^{9}$ For details about Eurostat's flash estimate see Preliminary GDP flash estimate in 30 days for Europe. For details about the ECB's forecast, see "A Guide to the Eurosystem/ECB Staff Macroeconomic Projection Exercises" (2016), The European Commission provides additional information here.

${ }^{10}$ For instance, Bloomberg relevance indexes are not available for U.S. states' GDP. Additionally, when the Bureau of Economic Analysis started publishing U.S. states' quarterly GDP in 2015, the data were released, on average, 5 months after the end of the quarter. Currently, statewide GDPs are released after 3 months, and unemployment rates after 20 days (relative to 5 days for the national figure). State-specific personal consumption expenditure is published at an annual frequency.
} 
Table 1 Macroeconomic Variables, Release Delays, and Relevance Indexes

\begin{tabular}{|c|c|c|c|c|c|c|c|}
\hline \multicolumn{2}{|c|}{$\begin{array}{l}\text { Country Series Name } \\
\end{array}$} & \multirow{2}{*}{$\begin{array}{l}\text { Units } \\
(3)\end{array}$} & \multicolumn{5}{|c|}{ "Freq. Transf. Delay Relevance Category } \\
\hline (1) & $(2)$ & & $(4)$ & $(5)$ & $(6)$ & $(7)$ & $(8)$ \\
\hline EA & Gross Domestic Product & SWDA, Mil.Ch.2010.EUR & $q$ & pca & 45 & 92.5 & Hard \\
\hline EA & Unemployment Rate & $\mathrm{SA}, \%$ & $\mathrm{~m}$ & $\operatorname{lin}$ & 30 & 67.5 & Hard \\
\hline EA & Industrial Turnover: Manufacturing & SWDA, $2015=100$ & $\mathrm{~m}$ & pch & 60 & 75 & Hard \\
\hline EA & IP: Industry excluding Construction & SA/WDA, $2015=100$ & $\mathrm{~m}$ & pch & 45 & 62.5 & Hard \\
\hline EA & Industrial Production: Construction & SA/WDA, $2015=100$ & $\mathrm{~m}$ & pch & 50 & 15 & Hard \\
\hline EA & PMI: Manufacturing Flash & SA, $50+=$ Expansion & $\mathrm{m}$ & $\operatorname{lin}$ & -7 & 90 & Soft \\
\hline EA & PMI: Services Business Activity Flash & SA, $50+=$ Expansion & $\mathrm{m}$ & $\operatorname{lin}$ & -7 & 70 & Soft \\
\hline EA & Retail Sales Volume Index & SA/WDA, $2015=100$ & $\mathrm{~m}$ & pch & 35 & 50 & Hard \\
\hline EA & Consumer Confidence Indicator, \% Balance & $\mathrm{SA}, \%$ & $\mathrm{~m}$ & lin & -2 & 75 & Soft \\
\hline EA & Business Climate Indicator & SA, std-dev pts & $\mathrm{m}$ & $\operatorname{lin}$ & -2 & 30 & Soft \\
\hline EA & Exports of Goods & SA/WDA,Thous.EUR & $\mathrm{m}$ & pch & 45 & 82 & Hard \\
\hline EA & Imports of Goods & SA/WDA, Thous.Euros & $\mathrm{m}$ & pch & 45 & 25 & Hard \\
\hline EA & EU 28 excl Malta: New Passenger Car Registrations & NSA, Units & $\mathrm{m}$ & pc1 & 20 & 45 & Hard \\
\hline FR & Gross Domestic Product & SWDA Mil.Chn.2014.Euros & q & pca & 45 & 89 & Hard \\
\hline FR & Registered Unemployed: Act. Seeking, Not Working & SWDA, EOP, Thous & $\mathrm{m}$ & pch & 25 & 37 & Hard \\
\hline FR & New Passenger Car Registrations & NSA, Units & $\mathrm{m}$ & pc1 & 5 & 90 & Hard \\
\hline FR & Industrial Production: Manufacturing & SA/WDA, $2005=100$ & $\mathrm{~m}$ & pch & 40 & 60 & Hard \\
\hline FR & Industrial Production: Construction & SA/WDA, $2005=100$ & $\mathrm{~m}$ & pch & 45 & 60 & Hard \\
\hline FR & HH Consumption Exp: Total Manufactured Goods & SA/WDA, Bil.chn.2005.Euros & $\mathrm{m}$ & pch & 30 & 17 & Hard \\
\hline FR & Business Survey: Order Books \& Demand, Manuf. & SA, \% Balance & $\mathrm{m}$ & $\operatorname{lin}$ & -7 & 11 & Soft \\
\hline FR & Turnover: Manufacturing & SWDA, $2005=100$ & $\mathrm{~m}$ & pch & 60 & 11 & Hard \\
\hline FR & PMI: Manufacturing Flash & SA, $50+=$ Expansion & $\mathrm{m}$ & $\operatorname{lin}$ & -7 & 97 & Soft \\
\hline FR & PMI: Services Flash & $\mathrm{SA}, 50+=$ Expansion & $\mathrm{m}$ & $\operatorname{lin}$ & -7 & 77 & Soft \\
\hline FR & Retail Sales Vol. excl Motor Vehic. \& Motorcyc. & SWDA, $2005=100$ & $\mathrm{~m}$ & pch & 60 & 55 & Hard \\
\hline FR & Household Survey: Overall Household Conf. Ind. & $\mathrm{SA}, \mathrm{LT}$ Avg $=100$ & $\mathrm{~m}$ & $\operatorname{lin}$ & -5 & 80 & Soft \\
\hline FR & BdF Mo Bus Survey: Business Sentiment Indicator & SA, Long-term Avg $=100$ & $\mathrm{~m}$ & $\operatorname{lin}$ & -6 & 51 & Soft \\
\hline FR & Composite Business Climate Indicator & NSA, LT Avg $=100$ & $\mathrm{~m}$ & $\operatorname{lin}$ & -7 & 11 & Soft \\
\hline FR & Total Imports including Military Equipment & SA, Mil.Euros & $\mathrm{m}$ & pch & 65 & 54 & Hard \\
\hline FR & Total Exports including Military Equipment & SA, Mil.Euros & $\mathrm{m}$ & pch & 65 & 51 & Hard \\
\hline GE & Gross Domestic Product & SWDA Bil.Chn.2015.Euros & q & pca & 45 & 80 & Hard \\
\hline GE & Registered Civilian Unemployment Rate & $\mathrm{SA}, \%$ & $\mathrm{~m}$ & $\operatorname{lin}$ & 3 & 68 & Hard \\
\hline GE & Job Vacancies [Unsubsidized] & SA, Thous & $\mathrm{m}$ & pch & 3 & 68 & Hard \\
\hline GE & Industrial Production including Construction & SA/WDA, $2005=100$ & $\mathrm{~m}$ & pch & 38 & 92 & Hard \\
\hline GE & Industrial Production: Construction & SA/WDA, $2005=100$ & $\mathrm{~m}$ & pch & 38 & 92 & Hard \\
\hline GE & Manufacturing Orders [Volume] & $\mathrm{SA} / \mathrm{WDA}, 2005=100$ & $\mathrm{~m}$ & pch & 35 & 91 & Soft \\
\hline GE & Industry Sales [Volume]: Manufacturing & SA/WDA, $2005=100$ & $\mathrm{~m}$ & pch & 35 & 91 & Hard \\
\hline GE & New Passenger Car Registrations & NSA, Number & $\mathrm{m}$ & pc1 & 15 & 48 & Hard \\
\hline GE & PMI: Manufacturing Flash & SA, $50+=$ Expansion & $\mathrm{m}$ & $\operatorname{lin}$ & -7 & 90 & Soft \\
\hline GE & PMI: Services Flash & SA, $50+=$ Expansion & $\mathrm{m}$ & $\operatorname{lin}$ & -7 & 73 & Soft \\
\hline GE & Retail Sales Volume excluding Motor Vehicles & SWDA, $2005=100$ & $\mathrm{~m}$ & pch & 30 & 62 & Hard \\
\hline GE & Ifo Business Climate Index: All Sectors & SA, $2005=100$ & $\mathrm{~m}$ & $\operatorname{lin}$ & -7 & 98 & Soft \\
\hline GE & GfK Consumer Climate & $\mathrm{SA}, \%$ & $\mathrm{~m}$ & $\operatorname{lin}$ & -5 & 92 & Soft \\
\hline GE & Exports of Goods & SA, Bil.Euros & $\mathrm{m}$ & pch & 40 & 98 & Hard \\
\hline GE & Imports of Goods & SA, Bil.Euros & $\mathrm{m}$ & pch & 40 & 44 & Hard \\
\hline IT & Gross Domestic Product & SA/WDA, Mil.Chn.2010.EUR & q & pca & 45 & 86 & Hard \\
\hline IT & Harmonized Unemployment Rate & $\mathrm{SA}, \%$ & $\mathrm{~m}$ & $\operatorname{lin}$ & 30 & 56 & Hard \\
\hline IT & Production in Construction & SA, $2005=100$ & $\mathrm{~m}$ & pch & 48 & 97 & Hard \\
\hline IT & IP: Total Industry excl Construction & SA/WDA, $2005=100$ & $\mathrm{~m}$ & pch & 40 & 94 & Hard \\
\hline IT & Manufacturing Orders & $\mathrm{SA}, 2005=100$ & $\mathrm{~m}$ & pch & 47 & 62 & Soft \\
\hline IT & Industrial Turnover & SA, $2005=100$ & $\mathrm{~m}$ & pch & 50 & 62 & Hard \\
\hline IT & Passenger Car Registrations & NSA, Units & $\mathrm{m}$ & pc1 & 3 & 37 & Hard \\
\hline IT & PMI: Manufacturing & SA, $50+=$ Expansion & $\mathrm{m}$ & $\operatorname{lin}$ & 3 & 90 & Soft \\
\hline IT & PMI: Services: Business Activy & $\mathrm{SA}, 50+=$ Expansion & $\mathrm{m}$ & $\operatorname{lin}$ & 3 & 70 & Soft \\
\hline IT & Retail Sales Excl Motor Vehicles \& Motorcyc. Value & $\mathrm{SA}, 2005=100$ & $\mathrm{~m}$ & pch & 35 & 72 & Hard \\
\hline IT & ISAE Consumer Confidence Indicator & SA, $1980=100$ & $\mathrm{~m}$ & $\operatorname{lin}$ & -5 & 90 & Soft \\
\hline IT & ISAE Business Confidence Indicator & $\mathrm{SA}, 2005=100$ & $\mathrm{~m}$ & $\operatorname{lin}$ & -5 & 55 & Soft \\
\hline IT & Merchandise Exports, fob & SA, Mil.Euros & $\mathrm{m}$ & pch & 45 & 93 & Hard \\
\hline IT & Merchandise Imports, cif & SA, Mil.Euros & $\mathrm{m}$ & pch & 45 & 74 & Hard \\
\hline
\end{tabular}

Note: This table provides the list of variables in our dataset. Moreover, for each variable, it provides the following details: economy to which the variable belongs; unit of measurement; observation frequency; transformation applied to the data; release delay, measured by the average days elapsed from the end of the reference period (month/quarter) to the date of the data release; Bloomberg relevance index; and category to which the variable belongs (soft/hard data). For most of our sample, GDP was released with an average of 45 days of delays. After October 2015, the publication delay for GDP diminished to an average of 30 days. 
sectors of the euro-area economy, as well as different types of data, such as hard and soft data. For instance, economists closely monitor variables about labor markets (e.g., the unemployment rate), the industrial sector (e.g., the index of industrial production, and industrial turnover), the construction sector (e.g., the index of production in construction), private consumption (e.g., retail sales, and car registrations), and the external sector (e.g., exports and imports of goods). However, economists look beyond these hard data-that is, those data collected by statistical agencies based on measurable quantities. They also closely monitor soft data-survey indexes that portray feelings and perceptions of economic agents about current and future economic prospects. Among the many monitored soft data sources are the Purchasing Managers' Index on large companies' economic perspectives, and the European Commission's indexes on consumer confidence and business climate 11

It is important to point out that we intentionally left out of this paper daily and weekly indicators, such as financial variables. As shown in Banbura, Giannone, Modugno, and Reichlin (2013) those data do not improve the performance of a now-casting model either during normal times or during the Great Recession, due to their noisy nature, and their detachment from the real economy if not for their low frequencies. We also left out some alternative types of data, such as from web searches, electronic transactions, and textual analyses. The ability of these alternative sources to improve timely estimates of economic activity is still subject to debate. For example, Larson and Sinclair (2020) show that Google Trends do not improve the accuracy of unemployment insurance claims now-casts either in normal times or in the time of COVID-19. However, we leave these avenues for future research. In this paper, we focus on formalizing how market participants monitor the euro-area data, and especially on the role of the multi-country dimension and of soft data in a traditional now-casting setting.

\footnotetext{
${ }^{11}$ In the surveys underlying these indexes, respondents generally answer questions on whether a particular economic condition improved, remained stable, or worsened. Final indexes are then weighted averages of responses indicating improvement or worsening of sectoral conditions.
} 
Figure 2 Timeliness of Euro-Area Data

(a) Release Delay of Variables by Country and Data Type

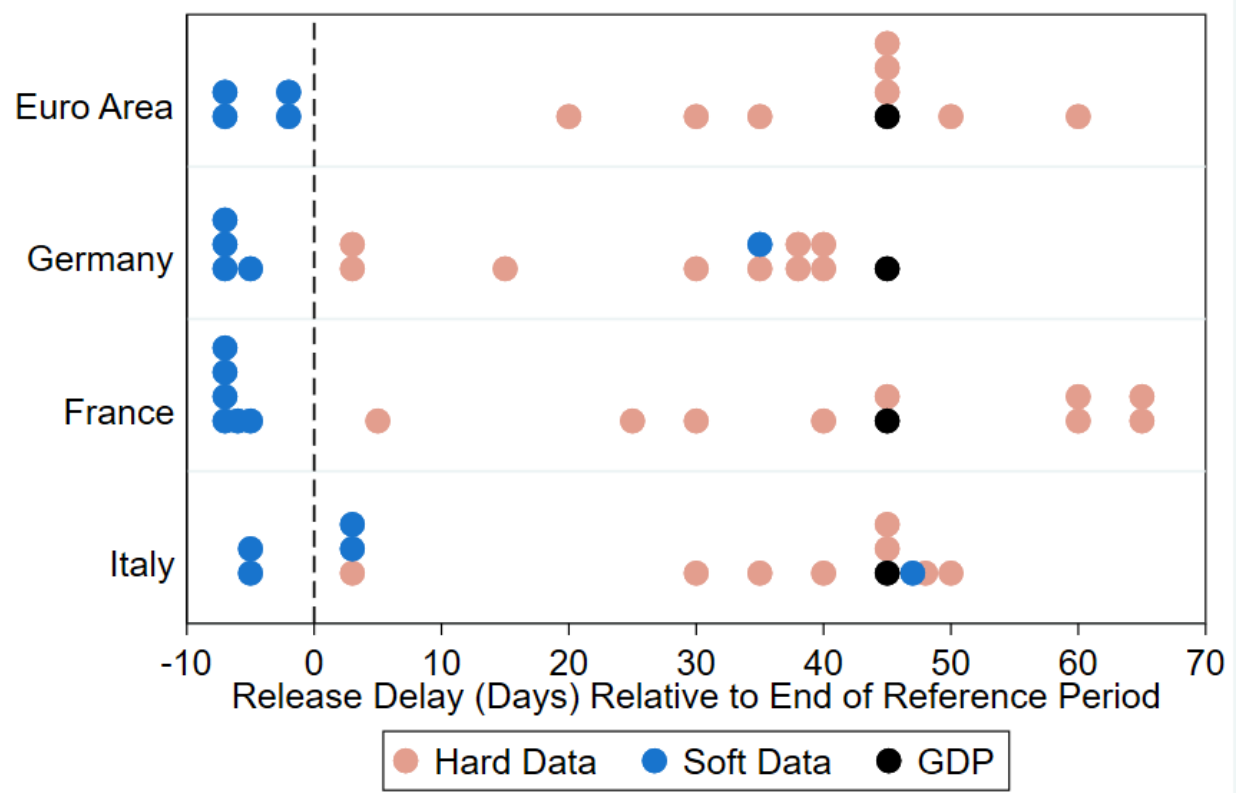

(b) Release Delay of Hard Data Variables: Euro Area and United States
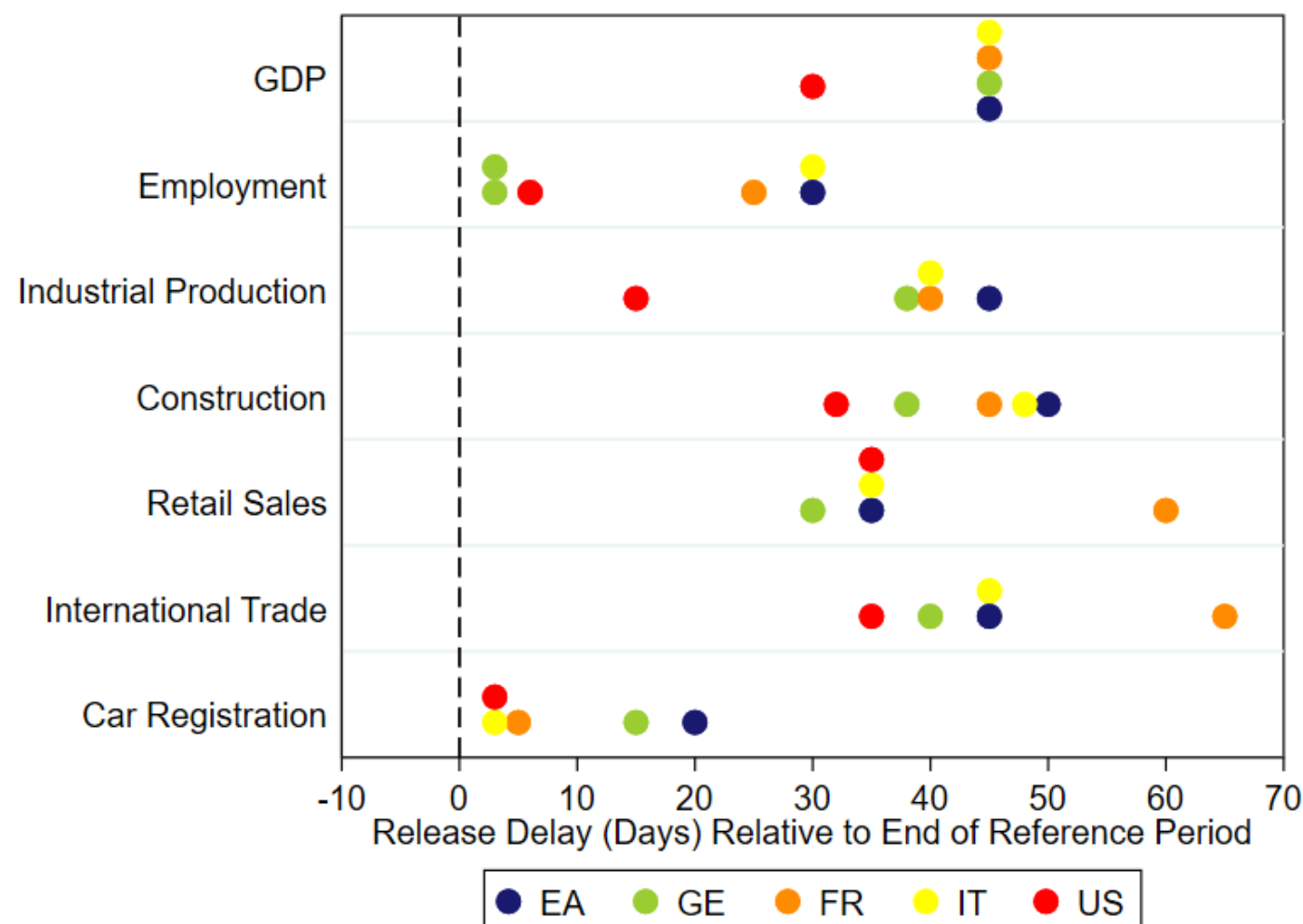

Note: The figures above present the release delay of the variables included in our dataset. In both figures, we measure release delay by the average days elapsed from the end of the reference period (month/quarter) to the date of the data release. For monthly data, the end of the period is the last day of the month, while for quarterly data it is the last day of the quarter. Figure 2a includes all variables in our dataset sorted by the economy they refer to (rows). Figure 20 focuses on major hard data variables including the release delay for United States variables. 


\subsection{The Timeliness of the Euro-Area Data}

One feature of our data set is that soft data for the euro area are available in a timely manner, while hard data are often released with a delay that is not only long, but also longer than for their U.S. counterparts. Figure 2a shows the release delay of each variable in our dataset, sorted by the economy it refers to (rows). We measure release delay by the average days elapsed from the end of the reference period (month/quarter) to the date of the data release. For monthly data, the end of the period is the last day of the month, while for quarterly data it is the last day of the quarter. Figure 2a shows that 31 out of 38 hard data variables (pink and black dots) are released with at least 30 days of delay, with these dots clustered on the right-hand-side of the figure. In contrast, 16 out of 20 soft data variables (blue dots) are released before the end of the month (dots clustered in the left-hand-side of the figure), consistent with the release delays of soft data of other advanced economies ${ }^{12}$ Figure $2 \mathrm{~b}$ compares the release delay of major hard-data variables (rows) across euro-area economies and the United States. The figure shows that U.S. variables (red dots) are most often released much earlier than their euro-area counterparts. Graphically, we see that most U.S. variables (red dots) are to the left of the euro-area variables (blue, green, orange, and yellow dots).

Finally, we learn from our dataset that country-specific and euro-area aggregate hard data are released asynchronously. Figure $2 \mathrm{~b}$ shows that, for most variables, the data of at least one major euro-area country is released before the data for the euro-area aggregate. This feature points to a potential gain in now-casting euro-area aggregate GDP using country-specific information. There are also euro-area aggregate variables that are released before their country counterparts, such as retail sales and international trade. This property also points to possible gains in using euro-area aggregate data to now-cast countries' GDP 13

\footnotetext{
${ }^{12}$ For instance, PMIs are released for many advanced countries, such as Canada and United Kingdom, between 10 days before and a couple days after the end of the reference month.

${ }^{13}$ The release of soft data is relatively synchronous across euro-area economies, leading us to focus on hard data in Figure $2 \mathrm{~b}$.
} 


\section{Econometric Framework}

In this section, we propose a multi-country now-casting model for the euro-area aggregate and its major countries - Germany, France, and Italy - as opposed to other scholars who have generally focused on single-economy now-casting models, including for the euro-area aggregate and its member countries ${ }^{14}$

\subsection{The Multi-Country Now-casting Model}

Our now-casting model is a dynamic factor model (DFM) that decomposes every economic indicator into three parts: (i) an euro-area component driven by a factor that affects all euro-area aggregate variables; (ii) a country-specific component driven by a factor that affects all variables from the specific country; (iii) an idiosyncratic component driven by indicator-specific shocks.

More precisely, we specify our model as follows:

$$
\begin{aligned}
& \mathbf{y}_{\mathbf{t}}=\boldsymbol{\Lambda} \cdot \mathbf{F}_{\mathbf{t}}+\mathbf{e}_{\mathbf{t}}, \\
& \mathbf{F}_{\mathbf{t}}=\mathbf{A} \cdot \mathbf{F}_{\mathbf{t}-\mathbf{1}}+\mathbf{u}_{\mathbf{t}}, \quad \mathbf{u}_{\mathbf{t}} \sim \text { i.i.d } \mathbf{N}(\mathbf{0}, \mathbf{Q}), \\
& \mathbf{e}_{\mathbf{t}}=\mathbf{D} \cdot \mathbf{e}_{\mathbf{t}-\mathbf{1}}+\mathbf{v}_{\mathbf{t}}, \quad \mathbf{v}_{\mathbf{t}} \sim \text { i.i.d } \mathbf{N}(\mathbf{0}, \mathbf{R}),
\end{aligned}
$$

\footnotetext{
${ }^{14}$ This class of models has been successfully employed for now-casting economic conditions in many economies: United States (Giannone, Reichlin, and Small, 2008; Lahiri and Monokroussos, 2013: Banbura et al., 2013; Bok, Caratelli, Giannone, Sbordone, and Tambalotti, 2018: Antolin-Diaz, Drechsel, and Petrella, 2020); Brazil (Bragoli, Metelli, and Modugno, 2015); Canada (Bragoli and Modugno, 2017); China (Yiu and Chow, 2010 and Giannone, Agrippino, and Modugno, 2013); the Czech Republic (Arnostova, Havrlant, Rùžièka, and Tóth| 2011); Japan (Bragoli, 2017| Hayashi and Tachi, 2020); New Zealand (Matheson, 2010); Norway (Aastveit and Trovik, 2012, and Luciani and Ricci, 2014); Switzerland (Siliverstovs, 2012); Turkey (Modugno, Soybilgen, and Yazgan, 2016); the United Kingdom (Anesti, Galvao, and Miranda-Agrippino 2018). For the euro area, researchers have developed separate models for the euro area and individual countries, ignoring cross-country information. In particular, now-casting models for the aggregate euro area have been proposed by Angelini, Bańbura, and Rünstler (2010), Camacho and Perez-Quiros (2010), Angelini, Camba-Mendez, Giannone, Reichlin, and Rünstler (2011), Bańbura and Rünstler (2011), Banbura et al.| (2011), Bańbura and Modugno (2014), and Carriero, Galvao, and Kapetanios (2019). Barhoumi, Darné, and Ferrara (2010) and Bessec and Doz (2014) applied the same framework for France. Marcellino and Schumacher (2010); Andreini, Senftleben-König, Hasenzagl, Reichlin, and Strohsal (2020) developed a model for Germany, de Antonio Liedo (2015) for Belgium, and D'Agostino, McQuinn, and O'Brien (2012) for Ireland. Rünstler, Barhoumi, Benk, Cristadoro, Den Reijer, Jakaitiene, Jelonek, Rua, Ruth, and Van Nieuwenhuyze, 2009 and Jansen, Jin, and de Winter, 2016 consider several European countries. Banbura et al. (2011, 2013); Luciani (2017); Bok et al. (2018); Stock and Watson (2017) provide surveys of the literature on now-casting.
} 
where $\mathbf{y}_{\mathbf{t}}$ denotes all monthly and quarterly standardized economic indicators; $\mathbf{F}_{\mathbf{t}}$ comprises the euro-area and country-specific factors; $\boldsymbol{\Lambda}$ represent the loadings of economic indicators on the factors; and $\mathbf{D}$ and $\mathbf{R}$ are diagonal matrices. We then assume a block structure in which each economic indicator loads only on its economy-specific factor:

$$
\left[\begin{array}{c}
\mathbf{y}_{\mathbf{t}}^{\mathbf{e a}} \\
\mathbf{y}_{\mathbf{t}}^{\mathrm{fr}} \\
\mathbf{y}_{\mathbf{t}}^{\mathbf{g e}} \\
\mathbf{y}_{\mathbf{t}}^{\mathrm{it}}
\end{array}\right]=\left[\begin{array}{cccc}
\Lambda^{\mathrm{ea}} & \mathbf{0} & \mathbf{0} & \mathbf{0} \\
\mathbf{0} & \Lambda^{\mathrm{fr}} & \mathbf{0} & \mathbf{0} \\
\mathbf{0} & \mathbf{0} & \Lambda^{\mathrm{ge}} & \mathbf{0} \\
\mathbf{0} & 0 & 0 & \Lambda^{\mathrm{it}}
\end{array}\right]\left[\begin{array}{c}
\mathrm{f}_{t}^{\mathrm{ea}} \\
\mathrm{f}_{t}^{\mathrm{fr}} \\
\mathrm{f}_{t}^{\mathrm{ge}} \\
\mathrm{f}_{t}^{\mathrm{it}}
\end{array}\right]+\left[\begin{array}{c}
\mathbf{e}_{\mathbf{t}}^{\mathrm{ea}} \\
\mathbf{e}_{\mathbf{t}}^{\mathrm{fr}} \\
\mathbf{e}_{\mathbf{t}}^{\mathrm{ge}} \\
\mathbf{e}_{\mathbf{t}}^{\mathrm{it}}
\end{array}\right]
$$

where we partition the data $\mathbf{y}_{\mathbf{t}}$ into indicators from the euro-area aggregate $\left(\mathbf{y}_{\mathbf{t}}^{\text {ea }}\right)$, Germany $\left(\mathbf{y}_{\mathbf{t}}^{\text {ge }}\right)$, France $\left(\mathbf{y}_{\mathbf{t}}^{\mathbf{f r}}\right)$, and Italy $\left(\mathbf{y}_{\mathbf{t}}^{\mathbf{i t}}\right)$; we assume one factor per economy: euro-area aggregate $\left(\mathrm{f}_{t}^{\text {ea }}\right)$, Germany $\left(\mathrm{f}_{t}^{\text {ge }}\right)$, France $\left(\mathrm{f}_{t}^{\mathrm{fr}}\right)$, and Italy, $\left(\mathrm{f}_{t}^{\mathrm{it}}\right)$; and we partition the idiosyncratic shocks $\mathbf{e}_{\mathbf{t}}$ and factor loadings $\boldsymbol{\Lambda}$ on a per "country" basis, analogous to Equation (4). This specification also assumes that all observable variables are coincident indicators for the common factors, and that the euro-area and country-specific common factors, Equation (2), evolve as a vector auto regression with one lag, $\operatorname{VAR}(1) 15$

We devise our multi-country now-casting model to capture the rich data dynamics and cross-country spillovers of the euro area, with the intuition for our main assumptions as follows. First, via block-structure, we impose that the data of each one of the four economies depends only on its own economy-specific factor, thus preserving the relationship between the economy's underlying data and its economy-specific factor. Second, we model the economy-specific factors with a $\operatorname{VAR}(1)$, which then allows euroarea economies leading in the business cycle to improve the now-casting of the lagging economies. Specifically, the euro-area aggregate factor can affect country-specific variables, while a country-specific factor can spill over to other country-specific variables, as well as to euro-area aggregate variables. The model also implies dynamic heterogeneity,

\footnotetext{
${ }^{15}$ This assumption amounts to restricting monthly observable variables to load only on the contemporaneous value of the common factors and quarterly variables to load on the contemporaneous and the first four lags of the common factors. Additionally, the loadings of quarterly variables are subject to the restriction that coefficients are proportional and satisfy the monthly-to-quarterly growth rate aggregation of Mariano and Murasawa (2003).
} 
as it does not impose that the effect of shocks is homogeneous across countries ${ }^{16}$

Our model is intentionally simple in many aspects. For instance, the framework is linear, parameters are time-invariant, and errors are homoskedastic. Moreover, we refrained from fine tuning many modelling choices through pretesting, instead focusing on simplicity and information reported by market-participants: the number of factors is set to one per economy; the selection of economic indicators and their transformations mirrors those continuously monitored by economists in business, the media, and policy institutions; and the number of lags for the common and idiosyncratic factors, Equations (2) - (3), is set to one. Despite the simplicity of our model, its forecasts provide automated and judgment-free predictions that compare well to best practices and expert judgments of professional private-sector forecasters (Consensus Economics) and the ECB, as we show in Section $5{ }^{17}$ The reason why, despite its simplicity, the proposed model perform well is the robustness of factor models to misspecification (e.g., Doz, Giannone, and Reichlin, 2012) and structural changes (e.g., Bates, Plagborg-Møller, Stock, and Watson, 2013), as well as its ability to parsimoniously capture business cycle co-movements (first discovered by Burns and Mitchell, 1946). Explicitly accounting for non-linearities, stochastic volatility, and fine-tuning other modeling choices is likely to lead to further improvement in the performance of our model. However, we leave these avenues for future research. In this paper, we focus on formalizing how market participants monitor the euro-area data, and especially on the role of the multi-country dimension and of soft data in a traditional now-casting setting.

\footnotetext{
${ }^{16}$ Other papers have proposed different solutions to address dynamic heterogeneity. For instance, D'Agostino, Giannone, Lenza, and Modugno (2016) includes 12 lags of the observable variables and common factors, maintaining parsimony via shrinkage methods. However, their model has only six observable variables.

${ }^{17}$ In Appendix A, we also show that the accuracy of our model compares well with those from two less parametrized models: (i) DFMs applied to the data of each economy separately, and (ii) a DFM that uses all the economic indicators and has only one euro-area factor. Despite the large number of parameters needed to model all countries jointly and allow for not perfectly synchronized business cycles, our multi-country model achieves a now-casting accuracy similar to (if not better than) those from the alternative models.
} 
Figure 3 Estimated Factors and Euro-Area Business Cycles

(a) Dynamic Factors of Euro-Area (EA) Economies

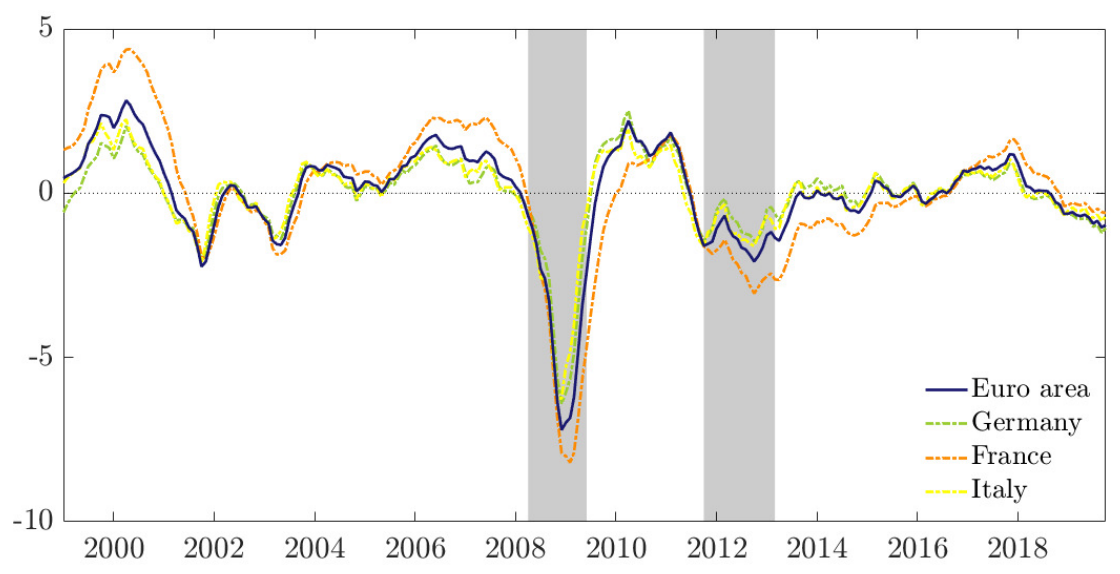

(b) Correlations with EA Factor

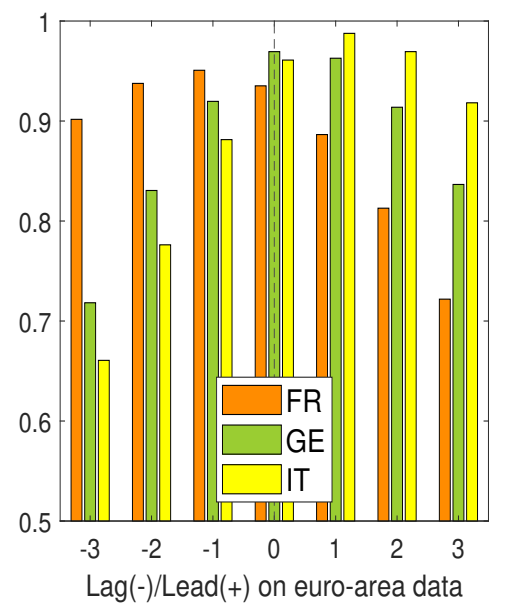

Note: Figure 3a displays the dynamic factors of each economy (euro-area aggregate, Germany, France, and Italy) estimated by our model. Shaded areas are euro-area recession periods as dated by the Center for Economic and Policy Research. Figure $3 b$ shows the cross-correlations among the dynamic factors by leading (positive x-axis) or lagging (negative x-axis) the factor of the euro-area aggregate.

\subsection{Estimation}

We estimate the model by quasi-maximum likelihood. Doz et al. (2012) show that, when the number of economic indicators is large and the factor structure is strong, likelihood based inference for DFM is viable and robust to non-Gaussianity and to the presence of weak correlation among idiosyncratic components. For the computation of the estimates we follow Bańbura and Modugno (2014), who modified the expectation-maximization algorithm of Dempster, Laird, and Rubin (1977) to estimate the parameters of a statespace model on datasets with arbitrary patterns of missing data.

As shown in Figure 3, the common factors for the euro area aggregate and its major countries tend to strongly co-move over time. The result is in line with Giannone et al. (2010) who document a strong commonality in euro-area business cycles. This suggests that economic signals from any country are likely to carry relevant information for the rest of the euro area, a feature that we exploit by modeling all economies simultaneously. Figure $3 \mathrm{~b}$ also shows the presence of some dynamic heterogeneity in the economic activity of euro-area economies, with lead-lag relationships between the common factor in different economies. Our model then takes these leads and lags into account using the dynamic 
interaction of the factors in the VAR of Equation (2).

\subsection{Pseudo-out-of-Sample Forecasts}

In Sections 4 and 5, we evaluate the performance of our multi-country now-casting model through out-of-sample exercises that give our model an information set similar to the one faced by market participants. These exercises have in common the following features. First, we assume that the data availability at each point in time of our sample is similar to the average release delay documented in Figure $2 \mathrm{a}{ }^{18}$ Second, for every month, we produce forecasts with the information set available on four different dates: the $7^{\text {th }}, 14^{\text {th }}$, $21^{\text {st }}$, and $28^{\text {th }}$. Third, for each of these dates, we forecast the previous quarter (back-cast), the current quarter (now-cast), and one quarter ahead (forecast). We then number each week of a reference quarter to indicate the timeline: weeks 0 to 12 for now-casts, negative weeks for forecasts, and weeks 13 onward for back-casts. Finally, we use an expanding estimation window that starts in January 1999 and generates its first forecast for January 2006.

Our pseudo-out-of-sample exercises also take into account the change in the release calendar of GDP. Until 2015, euro-area statistical agencies released their GDP estimates, on average, 45 days after the end of the reference quarter 19 For example, the GDP reading of 2014Q1 was released in mid-May 2014 for all the countries studied in this paper. Starting in 2016, the release calendar became timelier for the euro-area aggregate and France, with their GDP being released 30 days after the end of the quarter. Italy followed suit in May 2018 for its 2018Q1 GDP and Germany in July 2020 for its 2020Q2 GDP. Because of these changes in the GDP release calendar, we only calculate 4 backcasts for the GDP of each evaluated quarter, against 12 forecasts and 12 now-casts ${ }^{20}$

\footnotetext{
${ }^{18}$ For sections 4 5.1 and 5.2, we use the data vintage available in August 2019 because of the lack of real-time data for Germany, France, and Italy. For Section 5.3 we collect and use real-time data.

${ }^{19}$ For more details, see Box 4 of the ECB's Economic Bulletin Issue No. 4/2016.

${ }^{20}$ For each of the four weeks of the month, we produce three predictions: a back-cast, the prediction of GDP growth for the previous quarter (unless it has already been released); a now-cast, the prediction of GDP growth for the current quarter; and a forecast, the prediction of GDP growth for the following quarter. For example, on Feb/7/2014 we compute the back-cast of 2013Q4, the now-cast of 2014Q1 and the forecast of 2014Q2. With a total of four vintages per month, three months per quarter, and three estimations per vintage, we compute a total of 12 forecasts, 12 now-casts and 4 back-casts for each evaluated quarter, from 2006Q2 to 2019Q1.
} 


\section{Now-casting Results}

In this section, we show that our multi-country now-casting model rationalizes three properties of market participants' forecasts for the euro area. First, monitoring data releases in real-time, as market economists do, increases the accuracy of GDP forecasts (Section 4.1). Second, country-specific data contributes significantly to now-casting the euro-area aggregate GDP, and vice-versa (Section 4.2), consistent with the attention given by economists to both country-specific and aggregate data. Third, soft data are important for now-casting the euro area because of both their timeliness and their intrinsic relationship with GDP growth (Section 4.3), consistent with economists' focus on soft data.

\subsection{The Importance of Updating Now-casts in Real-Time}

We measure the forecasting accuracy of our multi-country now-casting model by computing its pseudo-out-of-sample forecast errors for the quarterly GDP growth of each economy (euro area, Germany, France, and Italy). Specifically, for the period from January 2006 to August 2019, we compute root mean square forecast errors (RMSFEs) as follows:

$$
R M S F E=\sqrt{\frac{\sum_{t=1}^{T}\left(\mathbb{E}\left[y_{t}^{c} \mid \Omega_{w}\right]-y_{t}^{c}\right)^{2}}{T}},
$$

where $T$ is the number of observations; $y_{t}^{c}$ is the realized value of the quarterly GDP growth of economy $c$ at an annualized rate in quarter $t$ for each of the four economies; and $\mathbb{E}\left[y_{t}^{c} \mid \Omega_{w}\right]$ is the prediction for $y_{t}^{c}$ conditional on the information set available, $\Omega_{w}$, at a particular week, $w$.

The accuracy of our model's GDP estimates steadily increases (Figure 4) as the release of an ever-larger number of economic indicators is incorporated by our model. More precisely, the RMSFEs from our now-casting model for all economies (orange lines) consis- 
Figure 4 Out-of-Sample Now-casting Performance

(a) Euro Area

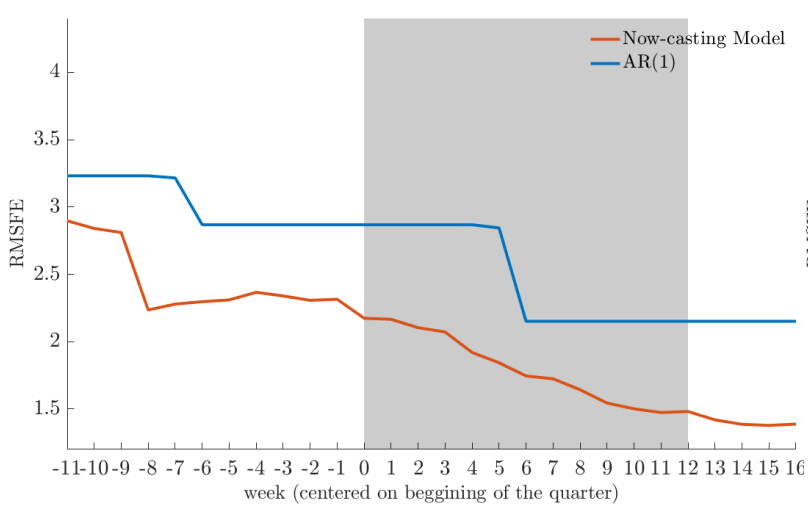

(c) France

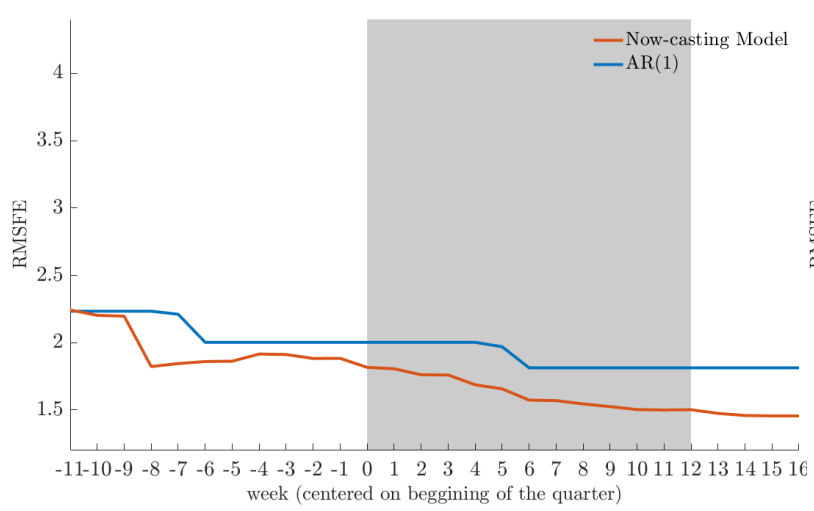

(b) Germany

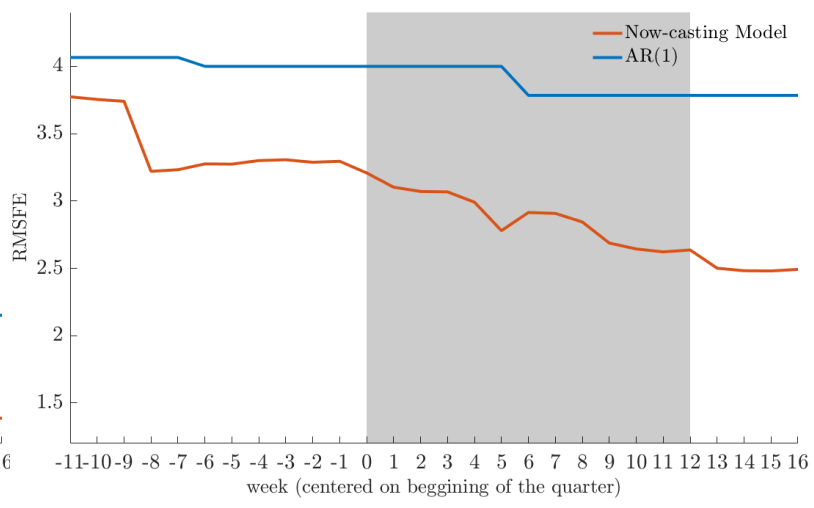

(d) Italy

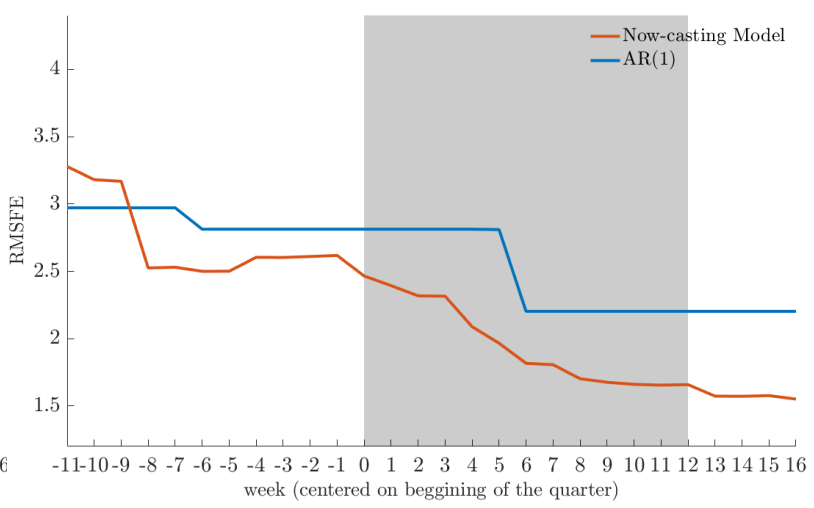

Note: Root mean square forecast errors (RMSFE), Equation (5), are calculated under the out-of-sample exercise described in Section 4.1. Orange line shows the RMSFEs for the multi-country now-casting model. Blue line shows the RMSFEs for an AR(1) model. The $x$-axis represents the weeks of the reference quarter, with negative numbers for weeks before the start of the quarter. Shaded area represents now-cast weeks (current quarter forecast).

tently fall throughout the forecasting horizon ${ }^{21}$ These results mirror the ability of market participants to increase the accuracy of their forecasts as they increase their information set (e.g., Loungani, 2001). Additionally, these results contrast with the constant RMSFEs of the benchmark auto-regressive model (blue line).

\subsection{Country Data Now-casts the Euro Area (and Vice-Versa)}

By jointly modeling the euro-area aggregate and its major countries, we show that data releases from one economy typically lead to important now-casting revisions on the others. Following Bańbura and Modugno (2010), we calculate the average news of now-casting

\footnotetext{
${ }^{21}$ In the Appendix, we also document that forecast errors from our now-casting model are larger during recessions. For details, see Figure D.1.
} 
the GDP growth of economy $c$ from variable $i$ at week $w$ as follows:

$$
N e w s_{w}^{i, c}=\frac{\sum_{t=1}^{T}\left(\left|\mathbb{E}\left[y_{t}^{c} \mid \Omega_{w(i)}\right]-\mathbb{E}\left[y_{t}^{c} \mid \Omega_{w-1}\right]\right|\right)}{T},
$$

where $T$ is the number of observations; $y_{t}^{c}$ is the GDP growth to be estimated; $w$ is the week of the reference quarter; $\mathbb{E}\left[y_{t}^{c} \mid \Omega_{w-1}\right]$ is the estimate of $y_{t}^{c}$ using the information set of all variables available at week $w-1$; and $\mathbb{E}\left[y_{t}^{c} \mid \Omega_{w(i)}\right]$ is the estimate of $y_{t}^{c}$ using the information set that includes variable $i$ released at week $w$ in addition to all the all variables available at week $w-1$. For instance, if we focus on the contribution of the euro-area aggregate PMI released in the week before the start of the reference quarter (week -1) to forecast German GDP, News ${ }_{-1}^{E A-P M I, g e}$ measures the average revision to the German GDP forecast arising from the release of the euro-area aggregate PMI.

To measure how data releases from one economy influence the now-cast revisions of other economies, we group news led by indicators of each of the euro-area economies. Thus, for every week in the forecasting, now-casting, and back-casting periods, Figure 5 shows the sizes of typical forecast revisions for GDP growth led by data from the euro area (blue), Germany (green), France (orange) and Italy (yellow). The figure also reports the news decomposition for the GDP growth of each one of these economies (Figures $5 a$ ad). Importantly, the overall size of now-cast revisions consistently decreases as we approach the GDP release date, consistent with the results from Section 4.1.

Not only are country-specific data important to predict euro-area aggregate GDP growth (Figure 5a), but the reverse is also true: euro-area data are important to predict country-specific GDP growth (Figures 5b $5 \mathrm{~d}$ ). For instance, during weeks -8 through 4 , French data (orange bars) generally lead to large revisions to the forecast of euro-area GDP. In some weeks during this early forecasting period, French data lead to revisions that are typically even larger than those from the euro-area data. Conversely, data releases from the euro-area aggregate and France generally lead to sizable forecast revisions to the German and Italian GDPs in the early weeks of the forecast.

These results rationalize the simultaneous monitoring of the euro-area aggregate and 
Figure 5 News Decomposition of GDP Growth: Origin of the Data

(a) Euro Area

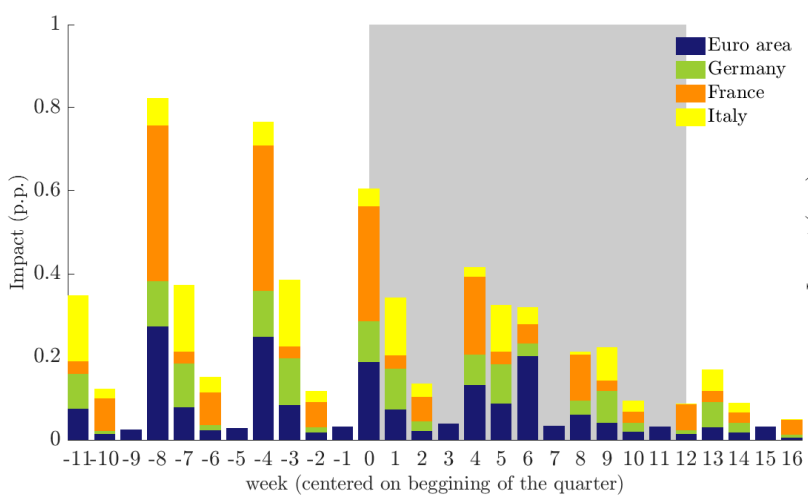

(c) France

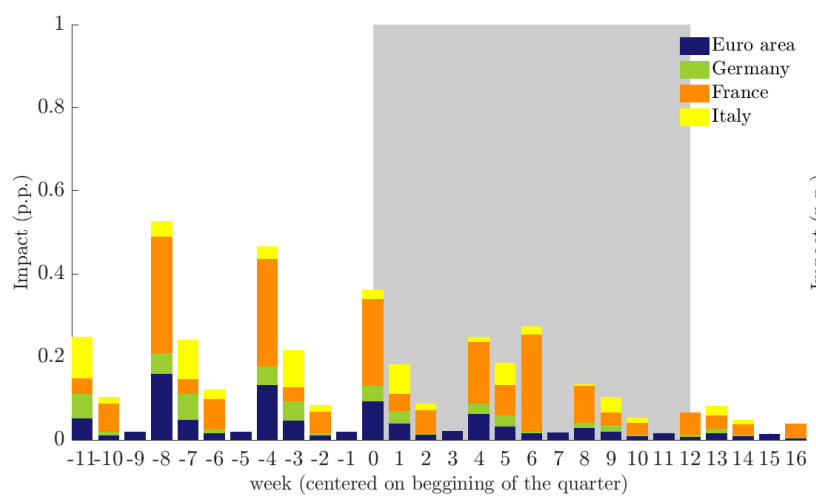

(b) Germany

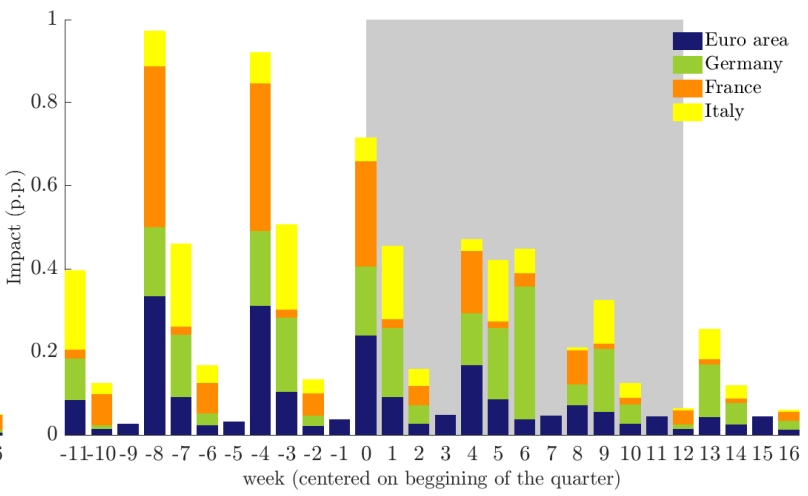

(d) Italy

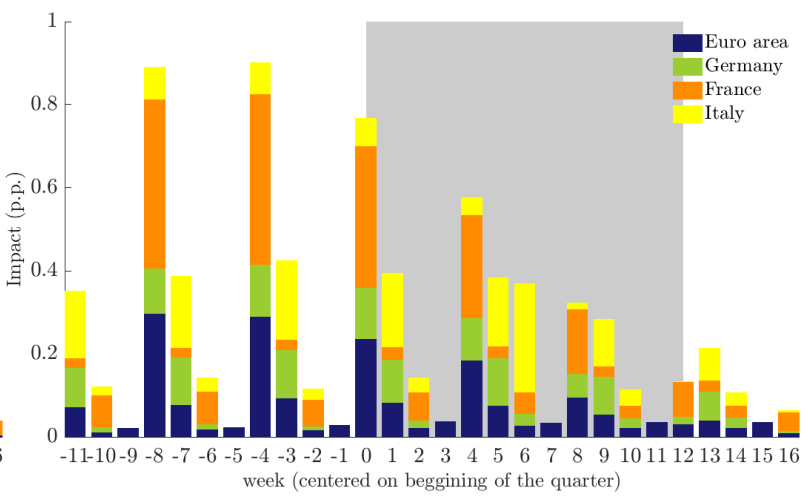

Note: News is calculated as the average of the (absolute) forecast revisions led by a particular data release, Equation (6). For the GDP growth of each economy (Figures 5 a $5 d$,), we group news from data releases about the euro area (blue bars), Germany (green bars), France (orange bars), and Italy (yellow bars). The x-axis represents the weeks of the reference quarter, with negative numbers for weeks before the start of the quarter. Shaded area represents now-cast weeks (current quarter forecast).

its major economies by market participants and policymakers, documented in Section 2.1. Economists simultaneously monitor these economies not only to ensure consistency in their cross-country forecasts, but also because the cross-country data are informative from a forecasting perspective.

\subsection{Soft Data are Important for Now-casting the Euro Area}

Releases of soft data typically lead to much larger now-casting revisions than those from hard data in all studied euro-area economies. To show this result, we group the news (Equation 6) led by hard (pink bars) and soft (blue bars) indicators from all economies 
Figure 6 News Decomposition of GDP Growth: Hard vs Soft Data

(a) Euro Area

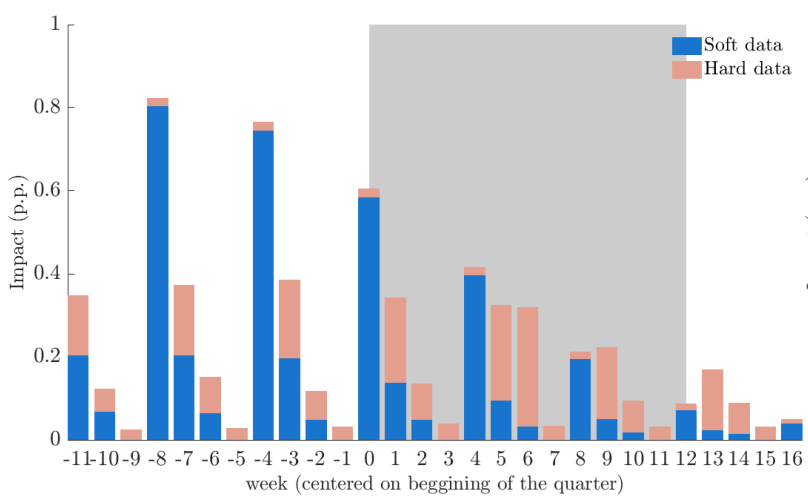

(c) France



(b) Germany

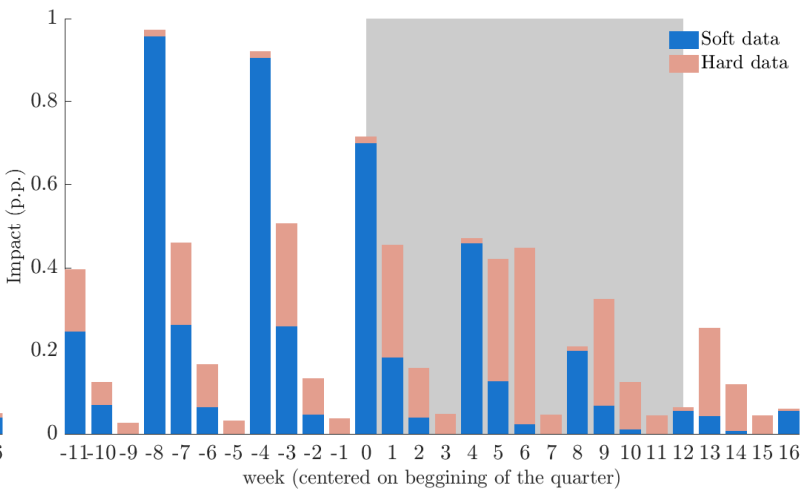

(d) Italy



Note: News is calculated as the average of the (absolute) forecast revisions led by a particular data release, Equation (6). For the GDP growth of each economy (Figures [6a [6d), we group news from releases of hard (pink bars) and soft (blue bars) data. The $x$-axis represents the weeks of the reference quarter, with negative numbers for weeks before the start of the quarter. Shaded area represents now-cast weeks (current quarter forecast).

(Figure 60. ${ }^{22}$ Releases of soft indicators have large implications for GDP forecasts as early as two months before start of the quarter, with average revisions still sizable in week 4 of the forecasted quarter. In contrast, releases of hard indicators generally lead to forecast revisions smaller than those from soft indicators until week 5 . Thereafter, forecast revisions led by hard data are relatively larger, but the overall size of all revisions quickly shrinks.

As emphasized by Giannone et al. (2006) and Gilbert et al. (2017), the information content of an economic indicator depends not only on its intrinsic relationship with the now-casted variable, but also on the timeliness of its release. To shed light on these two potential explanations for the now-casting performance of soft data, we build a

\footnotetext{
${ }^{22}$ Table 1 describes the classification of hard and soft data for each of the variables in our dataset.
} 
Figure 7 News Decomposition of GDP Growth: Anticipating Hard Data Releases

(a) Euro Area

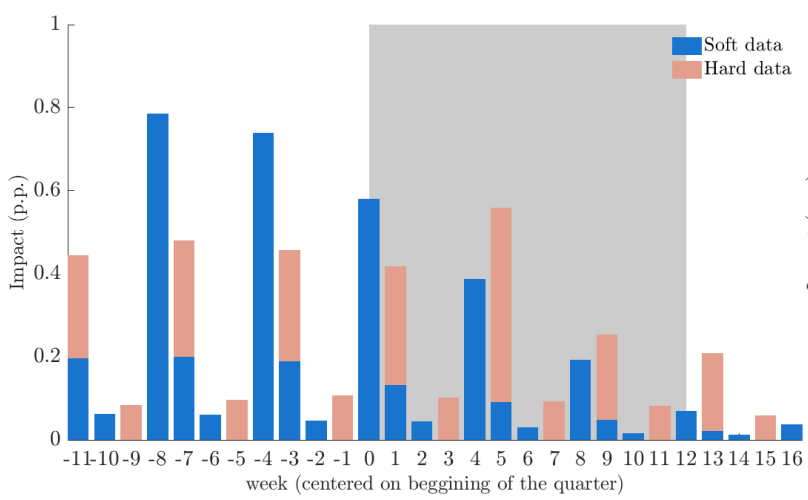

(c) France



(b) Germany

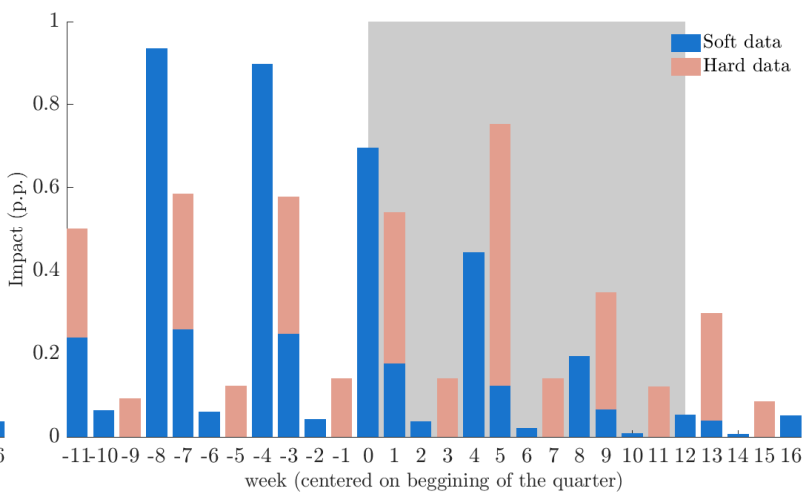

(d) Italy

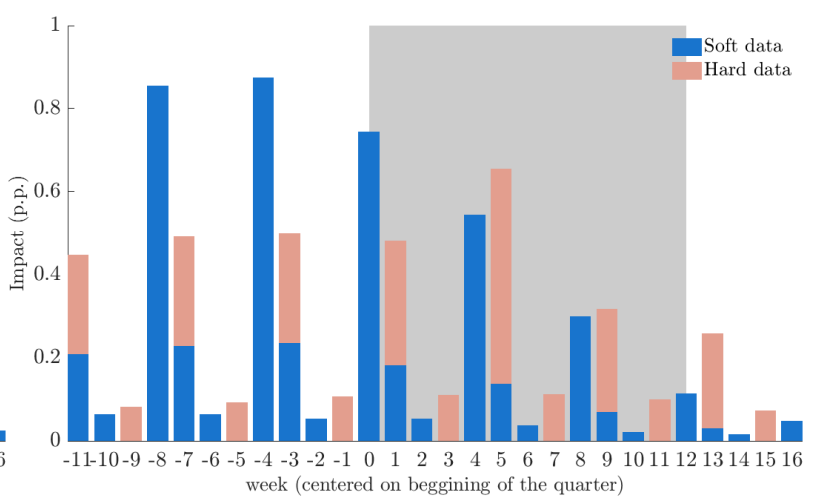

Note: News is calculated as the average of the (absolute) forecast revisions led by a particular data release, Equation (6). For the GDP growth of each economy (Figures 7a. (7d), we group news from releases of hard (pink bars) and soft (blue bars) data. Counterfactual news assume that releases of hard data are anticipated to follow a calendar similar to the United States. The $x$-axis represents the weeks of the reference quarter, with negative numbers for weeks before the start of the quarter. Shaded area represents now-cast weeks (current quarter forecast).

counterfactual dataset in which the release of hard data is anticipated to follow a calendar similar to the United States (Figure 2b).

Our counterfactual exercise shows that the importance of soft data to now-casting euro-area economies originates from both the timeliness of their releases and their intrinsic information content about economic conditions. Figure 7 shows that, under the counterfactual dataset, now-casting revisions from soft data (blue bars) remain sizable and essentially unchanged (relative to Figure 6) during weeks in which important soft indicators, such as PMIs, are released (e.g, weeks -8, -4, 0, and 4). Hard indicators, in turn, increase their importance (pink bars) to revisions of GDP, although remaining far from overturning the role of soft indicators. This result points to the informativeness of soft 
indicators about the GDP of euro-area economies even under a calendar that has timely hard data. If we, alternatively, delay soft data releases to match the calendar of hard data, soft data remain the predominant force in now-casting revisions (Appendix B).

We offer the following interpretation for the results of this section. Given the timely release calendar of soft indicators (Figure 2a), our multi-country now-casting model readily and heavily loads on them to produce its forecasts. Then, when the bulk of hard data for the quarter is released (near the end of the second month), a large share of the relevant forecasting information had already been conveyed by the soft data released earlier. Finally, the fact that soft data are both available in a timely manner and informative about the now-casted GDP leads to relatively small now-cast revisions in the last month of the quarter (weeks 9 through 12 of Figure 6).

The results from this section also indicate that the timeliness of soft data compensates for the long delay in the release of hard data in the euro area. While typically there is a trade-off between the timeliness of soft data and the precision of hard data, our results show that the euro-area soft data are both timely and relatively precise, consistent with results of Giannone, Reichlin, and Simonelli (2009) and Basselier, de Antonio Liedo, and Langenus (2018). Moreover, these results indicate that an effort to reduce the delay of releases of hard data could bring timely and accurate information to market participants and policymakers, but would likely add little from a now-casting perspective.

\section{Model performance in historical episodes}

In this section, we show that our model performs well in anticipating euro-area GDP growth in its previous three recessions ${ }^{23}$

\subsection{The Great Recession}

Figure 8 shows our forecasts closely tracking the economic activity during the period 2008-2009. Solid lines represent our model forecasts while dots represent GDP releases.

\footnotetext{
${ }^{23}$ Recession periods are those defined by the Center for Economic and Policy Research (CEPR).
} 
Figure 8 Now-casting Evolution of Euro-Area GDP Growth in 2008-09

(a) Now-casting Model and GDP Releases

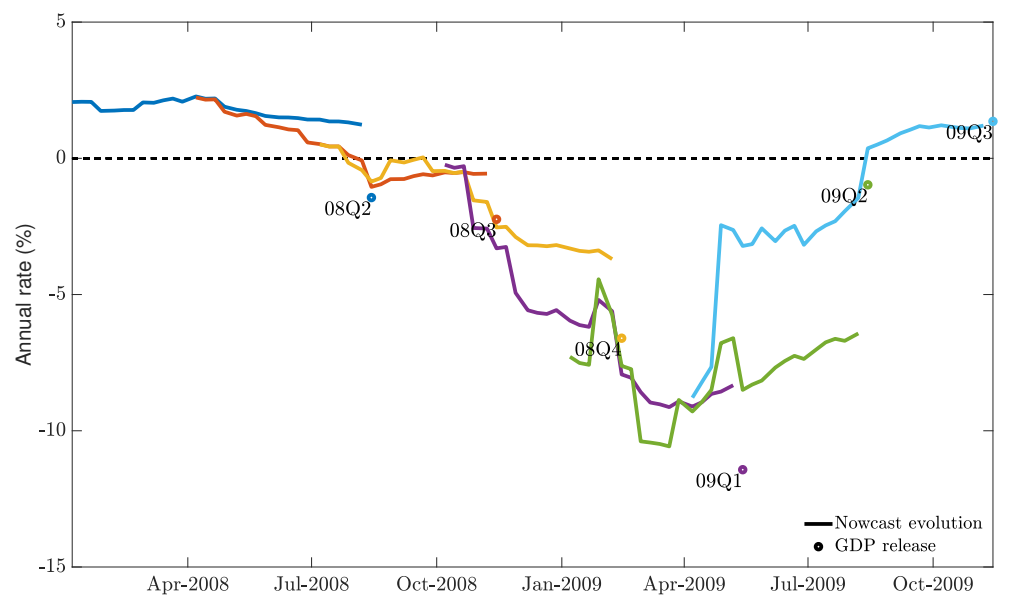

(b) Now-casting Model and Consensus Economics Forecasts



(c) Now-casting Model and ECB Forecasts

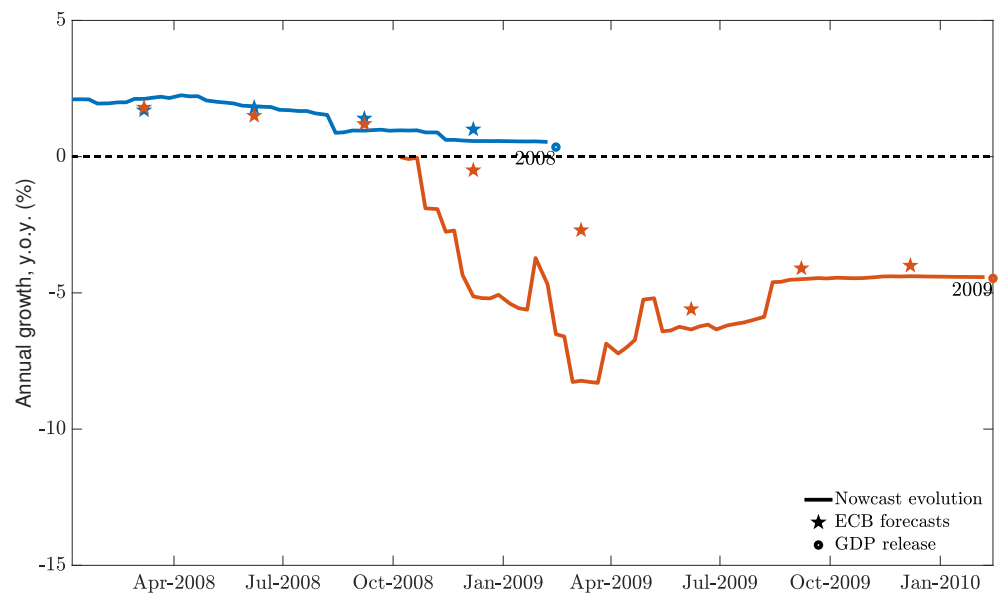

Note: Solid lines show the evolution of GDP growth now-casts for different quarters using our model (Section 3). Dates of GDP releases are from the release calendar schedule (Figure 2a). GDP growth in Figure $8 a$ is measured as quarter-on-quarter change at an annualized rate. GDP growth in Figure $\overline{8 b}$ is measured as 4-quarter change. GDP growth in Figure $8 \mathrm{c}$ is measured as year-over-quarter change. 
Looking closer, we observe this tracking performance in two ways. First, for a given forecasted quarterly GDP growth value, such as 2009Q3 in Figure 8a, the continuous flow of data consistently pushes the model prediction (light blue line) toward the GDP growth number released later. Second, the model is able to anticipate important shortterm trends in economic activity because it continually forecasts the previous, current and next-quarter GDP growth. We see this ability in periods such as July 2008, when estimates of moderate growth for 2008Q2 are accompanied by estimates of contraction for 2008Q3 and 2008Q4. In April 2009, the model behaved similarly but pointed to an improvement in activity.

Comparing our model forecasts with those from professional forecasters, we find that ours are more accurate for the deeper part of the recession. Figure $8 \mathrm{~b}$ shows the Consensus Economics forecasts and those from our model, with the Consensus' underestimating the drop in GDP growth by more than what our model would have done during the 2008Q32009Q1 period. The comparison between our forecasts and those from the ECB (Figure 8c paints a similar picture, with the important caveat that the ECB's forecasts were available only for GDP growth in year-over-year changes. In the start and end of the Great Recession, our forecasts were reasonably similar to those from Consensus and the ECB.

\subsection{The European Sovereign Debt Crisis}

The beginning of the euro-area recession led by the European sovereign debt crisis was marked by a rapid reversal of economic conditions. Indeed, professional forecasters and the ECB took several months to recognize these deteriorating conditions. In contrast, our model would have quickly signalled these adverse economic conditions.

In the first quarter of 2011, GDP grew at an annualized $2.9 \%$ and headline inflation reached $2.7 \%$ in March, with core-inflation only at $1.3 \%$ in the same month. The ECB then increased its policy interest rates in April, citing its mandate to "maintain inflation rates below, but close to, $2 \%$." However, in late May economic conditions began to quickly deteriorate, with our model estimates for 2011Q3 (top panel of Figure 1) dropping to 
Figure 9 Now-casting Evolution of Euro-Area GDP Growth in 2011-13

(a) Now-casting Model and GDP Releases



(b) Now-casting Model and Consensus Economics Forecasts

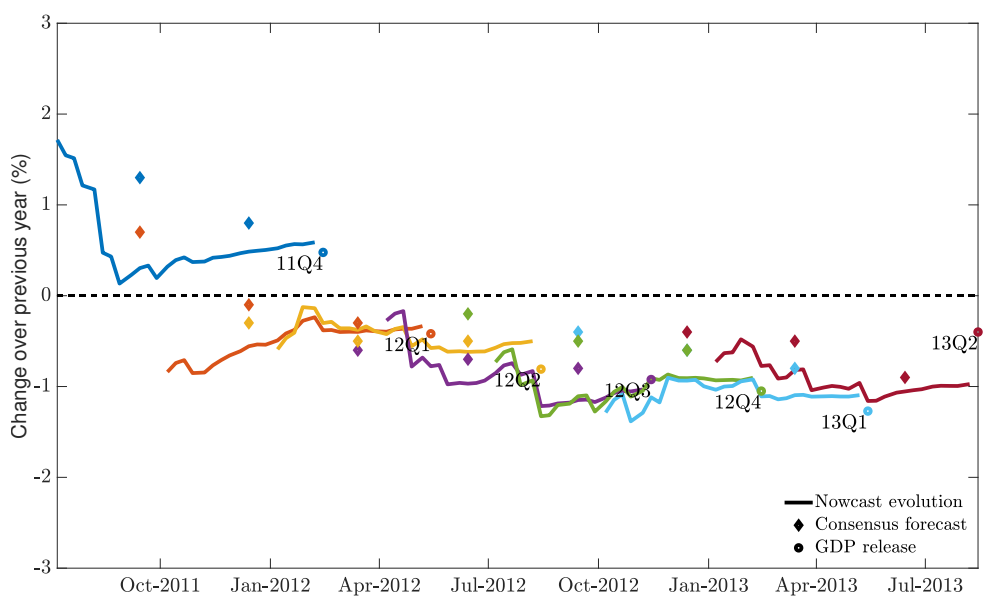

(c) Now-casting Model and ECB Forecasts

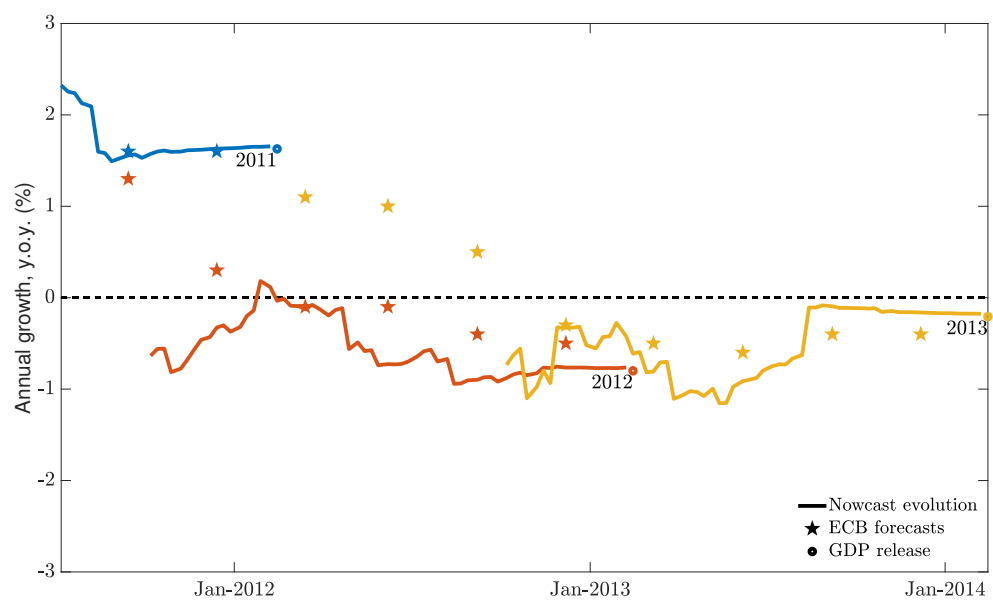

Note: Solid lines show the evolution of GDP growth now-casts for different quarters using our model (Section 3). Dates of GDP releases are from the release calendar schedule (Figure 2a). GDP growth in Figure $8 a$ is measured as quarter-on-quarter change at an annualized rate. GDP growth in Figure 86 is measured as 4-quarter change. GDP growth in Figure $8 \mathrm{C}$ is measured as year-over-quarter change. 
about $0 \%$ in late-July. During this period, the ECB held its policy rates steady in May and June, hiked them in July, and held steady again in early August, with its communications still emphasizing the inflation outlook ${ }^{24}$ Thereafter, economic conditions continued to weaken, as seen by the further decline in the model's projections for 2011Q3. Despite the weak activity data, headline inflation reached $3 \%$ in September, and the ECB held its policy rates steady in September and October. With inflation pressures arising mostly from energy prices (core-inflation never surpassed 1.6\% during 2011), the ECB finally decreased its policy rates in November.

The comparison between our model forecasts and other professional forecasters points to how timely our model could have been signaling the 2011 reversal in economic conditions. Figure $9 \mathrm{~b}$ compares our forecasts with the ones reported by Consensus Economics. It shows that in early-September 2011 our model was already forecasting a reading of about $0.4 \%$ for 2011Q4 GDP growth, while Consensus still had it at $1.3 \%$. The comparison with ECB forecasts (Figure $9 \mathrm{c}$ ) is more difficult because it used to report only its forecasts for year-over-year growth rates. Even so, by October 2011, our model would have forecasted a significant drop in expected GDP growth from 2011 to 2012, relative to a smoother pattern followed by the ECB forecasts. From mid-2012 onward, our model would have performed broadly in line with the ECB and Consensus forecasts. Figure 9 a also shows that our model tracked the economic conditions well during most of the recession.

\subsection{The Great Lockdown}

The Great Lockdown has imposed a collapse in economic activity of unprecedented speed and magnitude to the global economy. These circumstances present a particularly strin-

\footnotetext{
${ }^{24}$ In the press conference of the August 4, 2011, monetary policy meeting, ECB president Jean-Claude Trichet acknowledged some economic deceleration but emphasized the inflation outlook: "As expected, recent economic data indicate a deceleration in the pace of economic growth in the past few months, following the strong growth rate in the first quarter. Continued moderate expansion is expected in the period ahead. However, uncertainty is particularly high. For monetary policy, it is essential that recent price developments do not give rise to broad-based inflationary pressures. Inflation expectations in the euro area must remain firmly anchored in line with our aim of maintaining inflation rates below, but close to, $2 \%$ over the medium term." The sentence in italic was added to ECB statements in March, one meeting before it hiked policy rates in April.
} 
Figure 10 Euro-Area GDP Growth During the 2020 COVID-19 Crisis

Evolution of Estimates of Euro-Area GDP Growth in 2020Q2
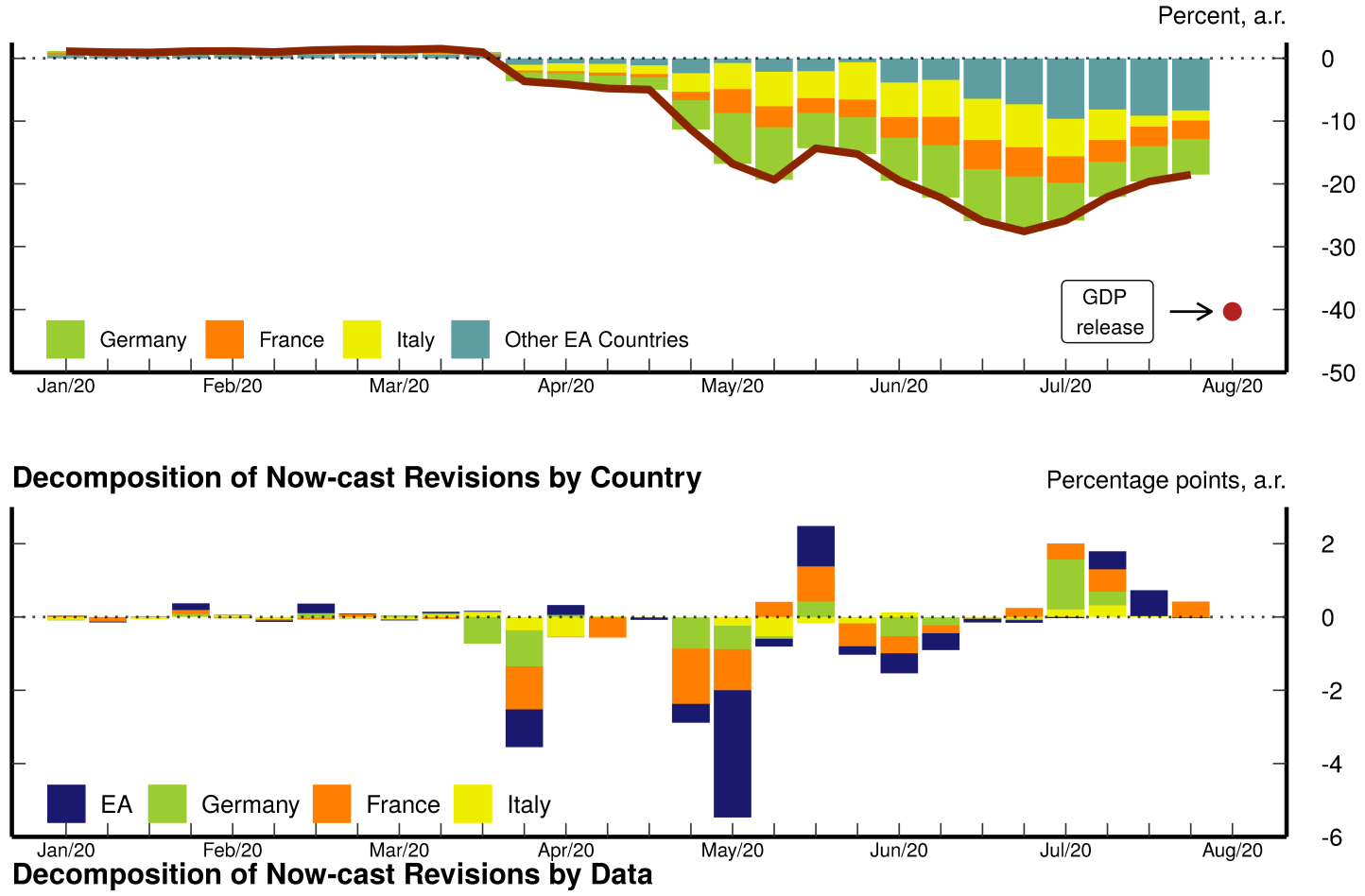

Decomposition of Now-cast Revisions by Data_ Percentage points, a.r.

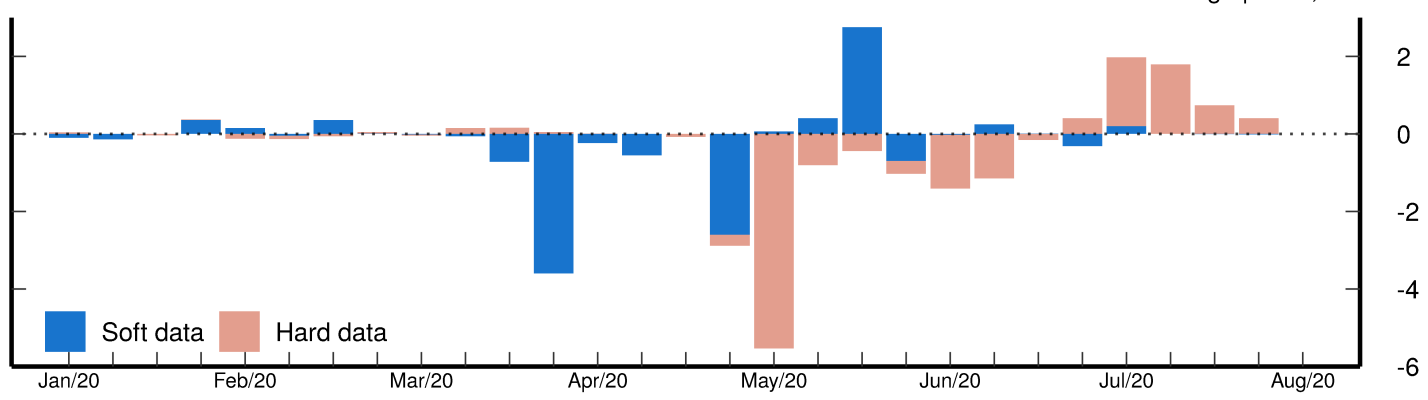

Note: Top panel presents weekly out-of-sample forecasts from our now-casting model. Vertical bars in top panel represents the contributions from Germany, France, Italy and the other euroarea countries to the euro-area GDP growth. Red dot in top panel represents the euro-area quarterly GDP growth of 2020Q2. Middle panel presents the decomposition of the model forecast revisions by the country of origin of the data, whereas the bottom panel presents revisions by hard/soft data. More details in Sections 3 and 4.

gent challenge to evaluate the performance of our model. Even so, our model was able to quickly signal the historic drop in economic activity in the euro area.

To highlight the abrupt deterioration in economic activity in the euro area and the lack of timely hard data for professional forecasters, we focus on the period from January 7 to July 31, 2020. During this period, governments imposed sudden shutdowns of large parts of the euro-area economy. For instance, Italy (the first major euro-area country 
affected by the pandemic) went from mild restrictions on social mobility in the end of February to an almost complete countrywide lockdown on March 1025 Moreover, with lockdown measures in the rest of the euro area becoming most stringent at the end of March, the hard data showing the economic repercussions of the pandemic only became available in mid-May, more than two months after the start of lockdowns.

Our model is then able to quantify the dramatic economic deterioration that happened in a matter of weeks. Highlighting both the precision and the timeliness of soft data for now-casting the euro area, our model made its first large downward revisions once it incorporated the release of flash PMIs at the end of March. For the euro-area aggregate (Figure 10), the forecasted GDP growth dropped from 1\% in March 21 to $-3.7 \%$ in March 28, only 2 weeks after the lockdown in Italy. The drop in GDP was broad, with negative contributions from Germany, France, Italy, and from the (implied) aggregate of the other euro-area countries (vertical bars in the top panel). Additional soft data indicators continued to push down the GDP forecast in the following weeks (blue bars in the lower panel), with the April PMIs reducing the GDP forecast to about $-12 \%$. In mid-May, hard data indicators for March, such as industrial production, were finally released and only consolidated the abysmal forecast for the period. The results for the major euro-area countries are similar to those for the aggregate region, and presented in the Appendix $\mathrm{C}$.

\section{Conclusion}

In this paper, we propose an econometric framework that formalizes how market participants and policymakers monitor the euro-area economic conditions. We simultaneously now-cast the economic activity of the euro-area aggregate and its three largest member countries - Germany, France, and Italy. The model delivers accurate predictions during the last two decades by providing effective solutions to the challenges of the Big Data problem at hand. Specifically, our model (i) processes a large volume of data, as it in-

\footnotetext{
${ }^{25}$ For instance, see the stringency index of lockdown measures compiled by Hale, Webster, Petherick, Phillips, and Kira (2020).
} 
cludes almost 60 time series covering the euro area and its three largest countries; (ii) has velocity in continuously updating GDP now-casts every time new data becomes available; and (iii) handles a large variety of data, such as times series from different sectors of the economy, available at different frequencies, and from different types of sources, such as hard data (measurable quantities) or soft data (perceptions about economic conditions).

Consistent with market participants' monitoring practices, our model shows that areawide and country-specific data provide informative signals to now-cast the economic conditions in the euro area and member countries. We also find that soft data, such as opinions surveys, are particularly important for now-casting the euro area since hard data are released with a substantial delay.

With economies around the world becoming both economically and financially ever more integrated, market participants and policymakers have gradually monitored an increasing number of economies in a simultaneous fashion. Our paper provides directions upon which researchers may follow to design models that help economists now-cast multicountry economic conditions, such as building world now-casting models. 


\section{References}

Aastveit, K. A., and Trovik, T. (2012). Nowcasting Norwegian GDP: The role of asset prices in a small open economy. Empirical Economics, 42(1), 95-119.

Altavilla, C., Giannone, D., and Modugno, M. (2017). Low frequency effects of macroeconomic news on government bond yields. Journal of Monetary Economics, 92, 31-46.

Andreini, P., Senftleben-König, C., Hasenzagl, T., Reichlin, L., and Strohsal, T. (2020). Nowcasting german gdp. Tech. rep., CEPR.

Anesti, N., Galvao, A. B., and Miranda-Agrippino, S. (2018). Uncertain Kingdom: Nowcasting GDP and its Revisions. Discussion Papers 1824, Centre for Macroeconomics (CFM).

Angelini, E., Bańbura, M., and Rünstler, G. (2010). Estimating and forecasting the euro area monthly national accounts from a dynamic factor model. OECD Journal: Journal of Business Cycle Measurement and Analysis, 2010/1.

Angelini, E., Camba-Mendez, G., Giannone, D., Reichlin, L., and Rünstler, G. (2011). Short-term forecasts of euro area GDP growth.

Antolin-Diaz, J., Drechsel, T., and Petrella, I. (2020). Advances in nowcasting economic activity: Secular trends, large shocks and new data. Tech. rep., Working paper.

Arnostova, K., Havrlant, D., Rùžièka, L., and Tóth, P. (2011). Short-Term Forecasting of Czech Quarterly GDP Using Monthly Indicators. Czech Journal of Economics and Finance (Finance a uver), 61(6), 566-583.

Banbura, M., Giannone, D., Modugno, M., and Reichlin, L. (2013). Now-Casting and the Real-Time Data Flow. In G. Elliott, C. Granger, and A. Timmermann (Eds.) Handbook of Economic Forecasting, vol. 2 of Handbook of Economic Forecasting, chap. 0, (pp. 195-237). Elsevier.

Bańbura, M., Giannone, D., and Reichlin, L. (2010). Large bayesian vector auto regressions. Journal of applied Econometrics, 25(1), 71-92. 
Banbura, M., Giannone, D., and Reichlin, L. (2011). Nowcasting. In Handbook on Economic Forecasting, vol. 2, (pp. 63-90). Oxford.

Bańbura, M., and Modugno, M. (2014). Maximum likelihood estimation of factor models on datasets with arbitrary pattern of missing data. Journal of Applied Econometrics, $29(1), 133-160$.

Bańbura, M., and Rünstler, G. (2011). A look into the factor model black box: Publication lags and the role of hard and soft data in forecasting GDP. International Journal of Forecasting, 27(2), 333-346.

Barhoumi, K., Darné, O., and Ferrara, L. (2010). Are disaggregate data useful for factor analysis in forecasting French GDP? Journal of Forecasting, 29(1-2), 132-144.

Basselier, R., de Antonio Liedo, D., and Langenus, G. (2018). Nowcasting real economic activity in the euro area: Assessing the impact of qualitative surveys. Journal of Business Cycle Research, 14(1), 1-46.

URL https://doi.org/10.1007/s41549-017-0022-9

Bates, B. J., Plagborg-Møller, M., Stock, J. H., and Watson, M. W. (2013). Consistent factor estimation in dynamic factor models with structural instability. Journal of Econometrics, 177(2), 289-304.

Bańbura, M., and Modugno, M. (2010). Maximum likelihood estimation of factor models on data sets with arbitrary pattern of missing data. Working paper series 1189, European Central Bank.

Bessec, M., and Doz, C. (2014). Short-term forecasting of French GDP growth using dynamic factor models. OECD Journal: Journal of Business Cycle Measurement and Analysis, 2013(2), 11-50.

Bok, B., Caratelli, D., Giannone, D., Sbordone, A. M., and Tambalotti, A. (2018). Macroeconomic nowcasting and forecasting with big data. Annual Review of Economics, 10, 615-643. 
Bragoli, D. (2017). Now-casting the Japanese economy. International Journal of Forecasting, 33(2), 390-402.

Bragoli, D., Metelli, L., and Modugno, M. (2015). The importance of updating: Evidence from a Brazilian nowcasting model. OECD Journal: Journal of Business Cycle Measurement and Analysis, 2015(1), 5-22.

Bragoli, D., and Modugno, M. (2017). A now-casting model for Canada: Do U.S. variables matter? International Journal of Forecasting, 33(4), 786-800.

Burns, A. F., and Mitchell, W. C. (1946). Measuring Business Cycles. NBER Books. National Bureau of Economic Research, Inc.

Camacho, M., and Perez-Quiros, G. (2010). Introducing the euro-sting: Short-term indicator of euro area growth. Journal of Applied Econometrics, 25(4), 663-694.

Carriero, A., Galvao, A. B., and Kapetanios, G. (2019). A comprehensive evaluation of macroeconomic forecasting methods. International Journal of Forecasting, 35(4), $1226-1239$.

Christiano, L. J., Eichenbaum, M., and Evans, C. L. (1999). Monetary policy shocks: What have we learned and to what end? Handbook of macroeconomics, 1, 65-148.

D'Agostino, A., McQuinn, K., and O'Brien, D. (2012). Nowcasting Irish GDP. OECD Journal: Journal of Business Cycle Measurement and Analysis, 2012(2), 21-31.

de Antonio Liedo, D. (2015). Nowcasting belgium. Eurostat Review on National Accounts and Macroeconomic Indicators, 2, 7-48.

Dempster, A. P., Laird, N. M., and Rubin, D. B. (1977). Maximum likelihood from incomplete data via the em algorithm. Journal of the Royal Statistical Society, Series $B, 39(1), 1-38$.

Doz, C., Giannone, D., and Reichlin, L. (2012). A Quasi-Maximum Likelihood Approach for Large, Approximate Dynamic Factor Models. The Review of Economics and Statistics, 94 (4), 1014-1024. 
D’Agostino, A., Giannone, D., Lenza, M., and Modugno, M. (2016). Nowcasting Business Cycles: A Bayesian Approach to Dynamic Heterogeneous Factor Models. In E. Hillebrand, and S. J. Koopman (Eds.) Dynamic Factor Models, vol. 35 of Advances in Econometrics, (pp. 569-594). Emerald Publishing Ltd.

Giannone, D., Agrippino, S. M., and Modugno, M. (2013). Nowcasting china real gdp. Tech. rep., Mimeo.

Giannone, D., Lenza, M., and Reichlin, L. (2010). Business Cycles in the Euro Area. In Europe and the Euro, NBER Chapters, (pp. 141-167). National Bureau of Economic Research, Inc.

Giannone, D., Reichlin, L., and Simonelli, S. (2009). Nowcasting euro area economic activity in real time: the role of confidence indicators. National Institute Economic Review, 210(1), 90-97.

Giannone, D., Reichlin, L., and Small, D. (2008). Nowcasting: The real-time informational content of macroeconomic data. Journal of Monetary Economics, 55 (4), $665-676$.

Giannone, D., Reichlin, L., and Small, D. H. (2006). Nowcasting gdp and inflation: The real-time informational content of macroeconomic data releases. Tech. rep., European Central Bank.

Gilbert, T., Scotti, C., Strasser, G., and Vega, C. (2017). Is the intrinsic value of a macroeconomic news announcement related to its asset price impact? Journal of Monetary Economics, 92, 78-95.

Hale, T., Webster, S., Petherick, A., Phillips, T., and Kira, B. (2020). Oxford covid-19 government response tracker. Blavatnik School of Government, 25.

Hayashi, F., and Tachi, Y. (2020). Nowcasting japan's gdp. Tech. rep., National Graduate Institute for Policy Studies, Japan. 
Jansen, W. J., Jin, X., and de Winter, J. M. (2016). Forecasting and nowcasting real GDP: Comparing statistical models and subjective forecasts. International Journal of Forecasting, 32(2), 411-436.

Lahiri, K., and Monokroussos, G. (2013). Nowcasting us gdp: The role of ism business surveys. International Journal of Forecasting, 29(4), 644-658.

Larson, W. D., and Sinclair, T. M. (2020). Nowcasting unemployment insurance claims in the time of COVID-19. CAMA Working Papers 2020-63, Centre for Applied Macroeconomic Analysis, Crawford School of Public Policy, The Australian National University.

Loungani, P. (2001). How accurate are private sector forecasts? cross-country evidence from consensus forecasts of output growth. International Journal of Forecasting, 17(3), $419-432$.

Luciani, M. (2017). Large-dimensional dynamic factor models in real-time: A survey. In G. L. Mazzi, and A. Ozyildirim (Eds.) Handbook on Cyclical Composite Indicators, (pp. 429-451). Eurostat.

Luciani, M., and Ricci, L. (2014). Nowcasting Norway. International Journal of Central Banking, 10(4), 215-248.

Marcellino, M., and Schumacher, C. (2010). Factor MIDAS for Nowcasting and Forecasting with Ragged-Edge Data: A Model Comparison for German GDP. Oxford Bulletin of Economics and Statistics, 72(4), 518-550.

Mariano, R. S., and Murasawa, Y. (2003). A new coincident index of business cycles based on monthly and quarterly series. Journal of Applied Econometrics, 18(4), 427-443.

Matheson, T. D. (2010). An analysis of the informational content of new zealand data releases: The importance of business opinion surveys. Economic Modelling, 27(1), $304-314$.

McCoy, J., Modugno, M., Palazzo, B., and Sharpe, S. A. (2020). Macroeconomic News 
and Stock Prices Over the FOMC Cycle. Feds notes, Board of Governors of the Federal Reserve System (U.S.).

Modugno, M., Soybilgen, B., and Yazgan, E. (2016). Nowcasting Turkish GDP and news decomposition. International Journal of Forecasting, 32(4), 1369-1384.

Rünstler, G., Barhoumi, K., Benk, S., Cristadoro, R., Den Reijer, A., Jakaitiene, A., Jelonek, P., Rua, A., Ruth, K., and Van Nieuwenhuyze, C. (2009). Short-term forecasting of gdp using large datasets: a pseudo real-time forecast evaluation exercise. Journal of forecasting, 28(7), 595-611.

Siliverstovs, B. (2012). Keeping a finger on the pulse of the economy: Nowcasting Swiss GDP in real-time squared. Kof working paper, KOF Swiss Economic Institute, ETH Zurich.

Stock, J. H., and Watson, M. W. (2017). Twenty years of time series econometrics in ten pictures. Journal of Economic Perspectives, 31(2), 59-86.

Yiu, M. S., and Chow, K. K. (2010). Nowcasting Chinese GDP: information content of economic and financial data. China Economic Journal, 3(3), 223-240. 


\section{A Alternative Models and Performance Comparisons}

To better understand the now-casting gains of our multi-country model, we build two alternative models. We choose these models to show that, to produce accurate now-casts for the euro area and its major economies, it is important to (i) use the data from all these economies, and (ii) take into account the cross-country spillovers of these economies. The first alternative model applies the general DFM structure to the data of each economy separately and is equivalent to a restricted version of the multi-country model, Equations (1) - (4), in which A is diagonal. We call these DFMs Single Factor Euro Area; Single Factor Germany; Single Factor France; and Single Factor Italy. Importantly, there are no cross-country spillovers in these single factor DFMs. In our second alternative model, Single Factor Euro Area and Countries DFM, we jointly now-cast all four economies using one factor, the only one allowed in Equation (2). The Single Factor Euro Area and Countries DFM uses the data from all economies, but it allows neither countryspecific factors, nor cross-country spillovers. Moreover, the Single Factor Euro Area and Countries imposes that the effect of its common factor is homogeneous-that is, the response of all economic indicators to changes in the factor is the same, up to a constant of proportionality related to the factor loadings.

Figure A.1 summarizes the out-of-sample performances of all now-casting models, including the Multi-Country baseline model. In our out-of-sample exercise, the RMSFEs of all models and economies consistently fall as we get closer to the GDP release (Figure A.1). This finding indicates that incorporating incoming data into the information set of our models, on average, reduces the distance between the forecasted GDP growth and the actual GDP growth later released. There is also a substantial drop in all RMSFEs around eight weeks before the start of the forecasted quarter, which is explained by the release of PMIs and sentiment indicators.

The results for the euro-area aggregate (Figure A.1a) show a clear hierarchy across models, with the Multi-Country DFM performing best. The Single Factor Euro Area DFM displays the highest RMSFEs, with this model using only the data specific to the euro-area aggregate (blue line). When we add the data of the three euro-area major 
Figure A.1 Out-of-Sample Performance of Different Now-casting Models

(a) Euro Area

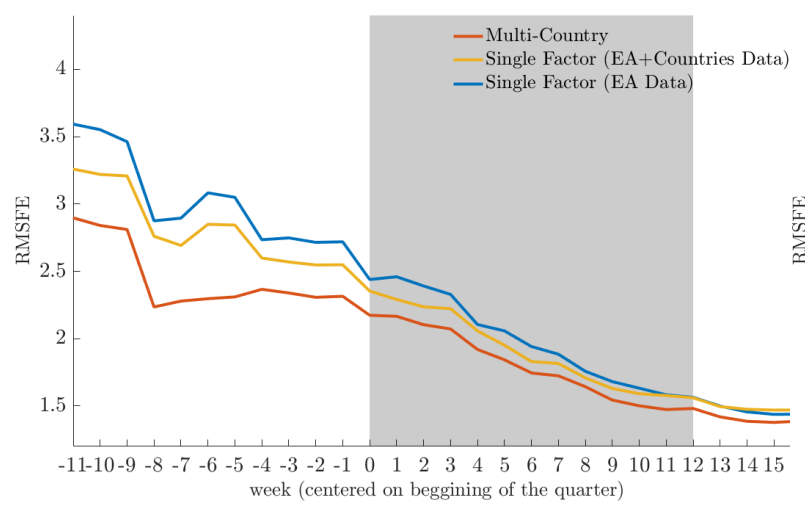

(c) France

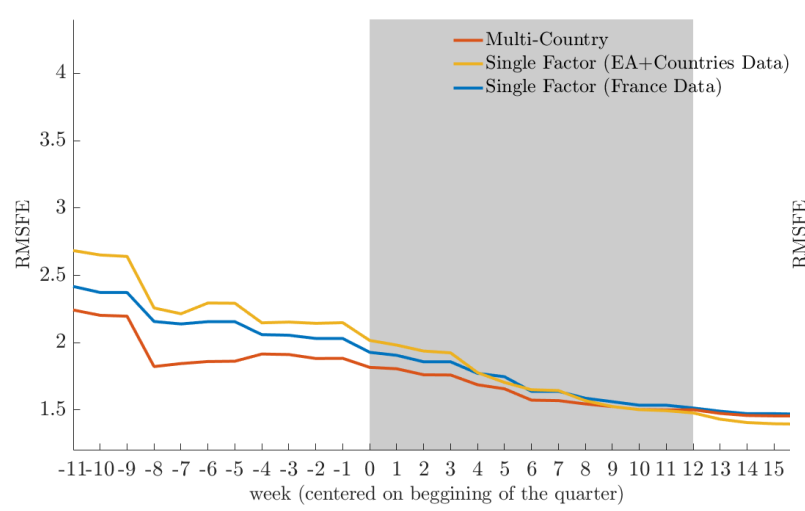

(b) Germany

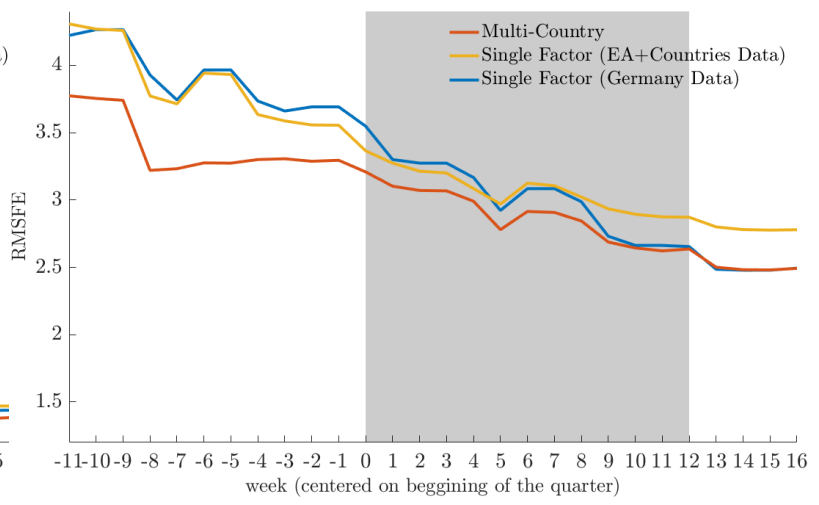

(d) Italy

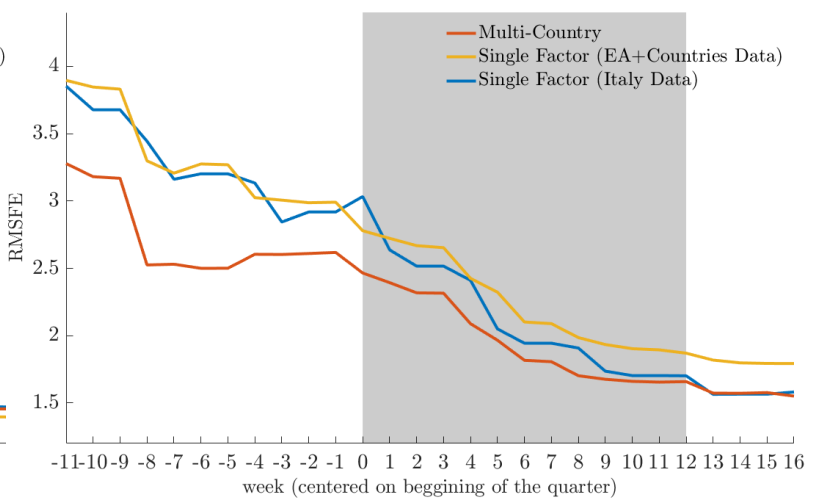

Note: Root mean square forecast errors (RMSFE), Equation (5), are calculated under the out-of-sample exercise described in Section 3.3 . The x-axis represents the weeks of the reference quarter, with negative numbers for weeks before the start of the quarter. Shaded area represents now-cast weeks (current quarter forecast).

countries while keeping the structure of the dynamic factor model unchanged (Single Factor Euro Area and Countries DFM), we improve the now-casting performance for the euro-area aggregate. In fact, the RMSFEs of the Single Factor Euro Area and Countries DFM (yellow line) are consistently lower than those of the Single Factor Euro Area DFM (blue line). Finally, when we both use the data of all four economies and model the dynamic relationship of these economies (Multi-Country DFM), we achieve the best performance. The RMSFEs of the Multi-Country DFM (red line) are lower than those of the two previous models. Of note, the difference in performance across models becomes much smaller in the back-cast period.

The now-casting improvement driven by jointly modeling euro-area economies and their dynamic relationship is also compelling for the major euro-area countries. For Ger- 
many (Figure A.1b), France (Figure A.1c), and Italy (Figure A.1d), our Multi-Country DFM performs best across the many different forecast horizons. However, in contrast to the euro-area aggregate, there is not a clear ranking in the performance of the Single Factor Country DFMs and Single Factor Euro Area and Countries DFM across the three euro-area countries. These results emphasize once more the need to model these economies jointly and exploit their lead-lag relationship. If one focuses only on jointly modeling these economies to take advantage of their non-synchronous release schedule, the performance gains might not be significant, as the comparison between the Single Factor Euro Area and Countries DFM and the Single Factor Country DFMs shows. 


\section{B Counterfactual: Postponing Soft Data Releases}

In this section, we build a counterfactual dataset in which the release of soft data matches the calendar of hard data. This exercise shows that the importance of soft data to nowcasting euro-area economies originates from both the timeliness of their releases and their intrinsic information content about economic conditions. Figure B.1 shows that, under the counterfactual dataset, the share of now-casting revisions led by soft data (blue bars) relative to overall revisions decrease in the forecasting horizon (compared to Figure 6). This result is consistent with the timeliness of soft data releases playing an important role in the real-time monitoring of economic conditions in the euro area. However, nowcasting revisions from soft data remain sizable, accounting for at least half of revisions during weeks in which soft indicators are (counterfactually) released. This result points to the informativeness of soft indicators about the GDP of euro-area economies even under this delayed release calendar. Hard indicators increase their importance (pink bars) to revisions of GDP, although they are far from taking over the role of soft indicators.

For this section, we assume the following delays in releases, which are roughly equivalent to postponing the release of soft indicators by about two months.:

- Euro area: consumer confidence, business climate, manufacturing PMI and services PMI matching the release of the euro-area industrial production;

- Germany: GfK consumer climate, Ifo business climate, manufacturing PMI and services PMI matching the release of Germany's industrial production;

- France: manufacturing business survey (order books \& demand), household confidence, BdF business sentiment, composite business climate, manufacturing PMI and services PMI matching the release of France's industrial production;

- Italy: ISAE consumer confidence, ISAE business confidence, manufacturing PMI and services PMI matching the release of Italy's industrial production. 
Figure B.1 News Decomposition of GDP Growth: Postponing Soft Data Releases

(a) Euro Area

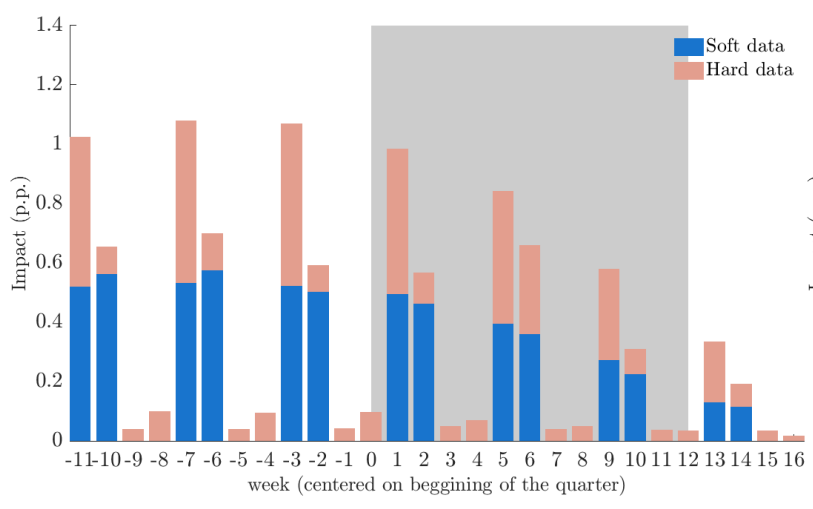

(c) France

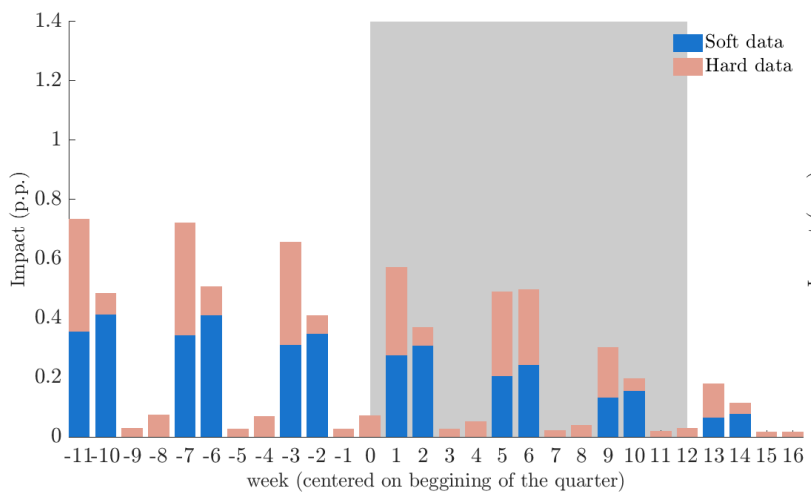

(b) Germany

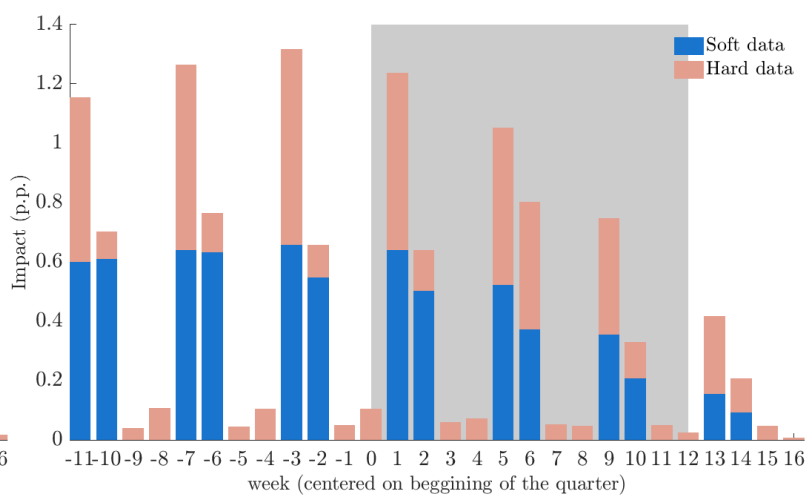

(d) Italy

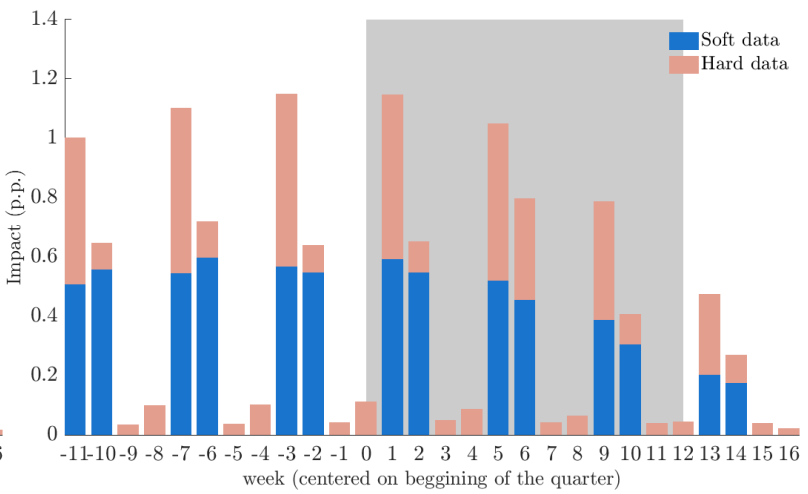

Note: News is calculated as the average of the (absolute) forecast revisions led by a particular data release, Equation (6). For the GDP growth of each economy (Figures B.1a B.1d), we group news from releases of hard (pink bars) and soft (blue bars) data. Counterfactual news assume that releases of soft data are postponed, following a calendar similar to the industrial production of the associated country. The x-axis represents the weeks of the reference quarter, with negative numbers for weeks before the start of the quarter. Shaded area represents nowcast weeks (current quarter forecast). 


\section{The 2020 COVID-19 Crisis}

Figure C.1 Germany GDP Growth During the 2020 COVID-19 Crisis

\section{Evolution of Estimates of Germany GDP Growth in 2020Q2}

Percent, a.r

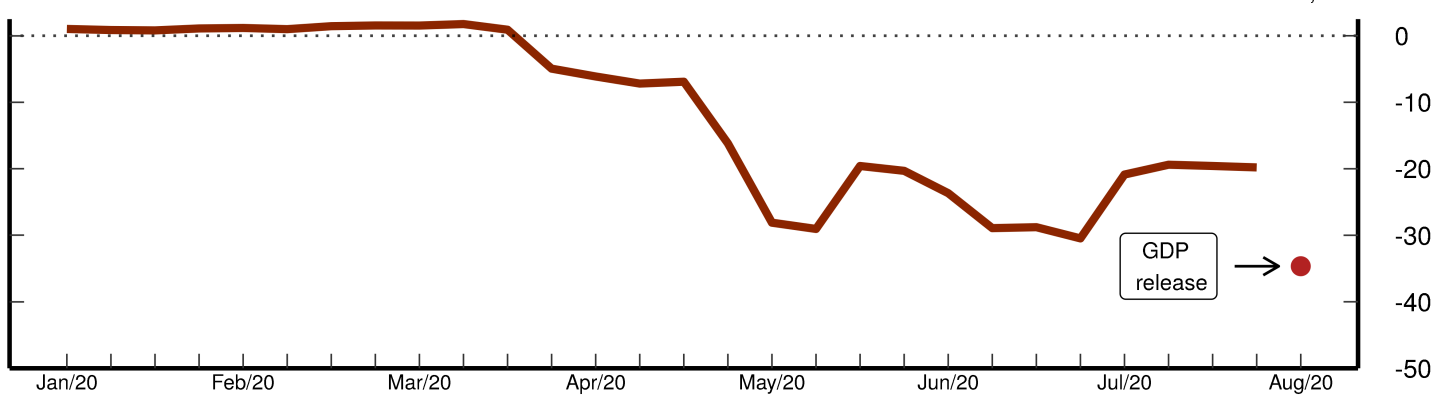

Decomposition of Now-cast Revisions by Country Percentage points, a.r.

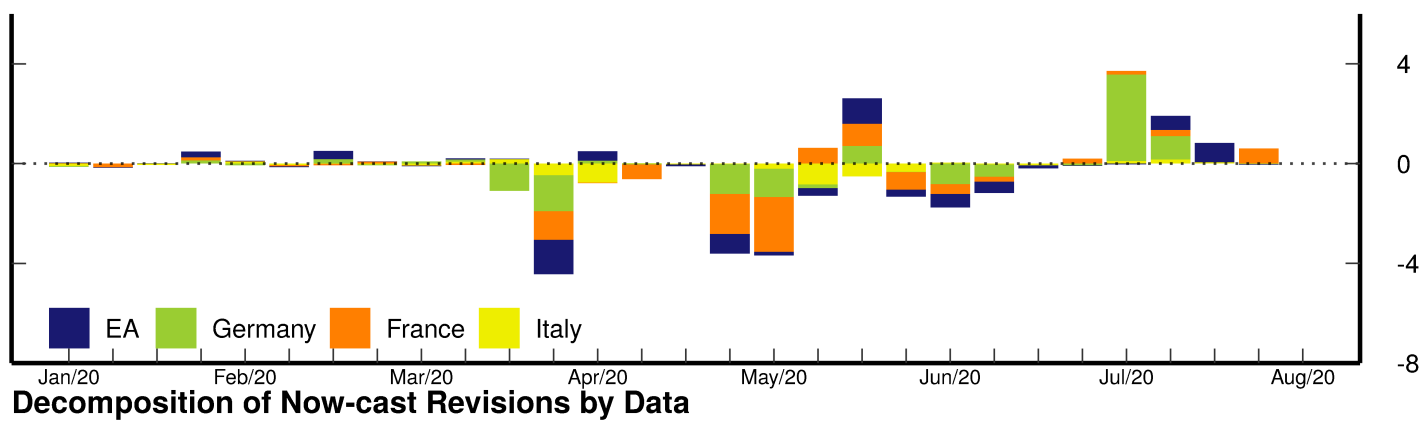

Percentage points, a.r.



Note: Top panel presents weekly out-of-sample forecasts from our now-casting model. Red dot in top panel represents Germany quarterly GDP growth of 2020Q2. Middle panel presents the decomposition of the model forecast revisions by the country of origin of the data, whereas the bottom panel presents revisions by hard/soft data. Revisions due to estimation update are not shown. More details in Sections 3 and 4. 
Figure C.2 France GDP Growth During the 2020 COVID-19 Crisis

\section{Evolution of Estimates of France GDP Growth in 2020Q2}
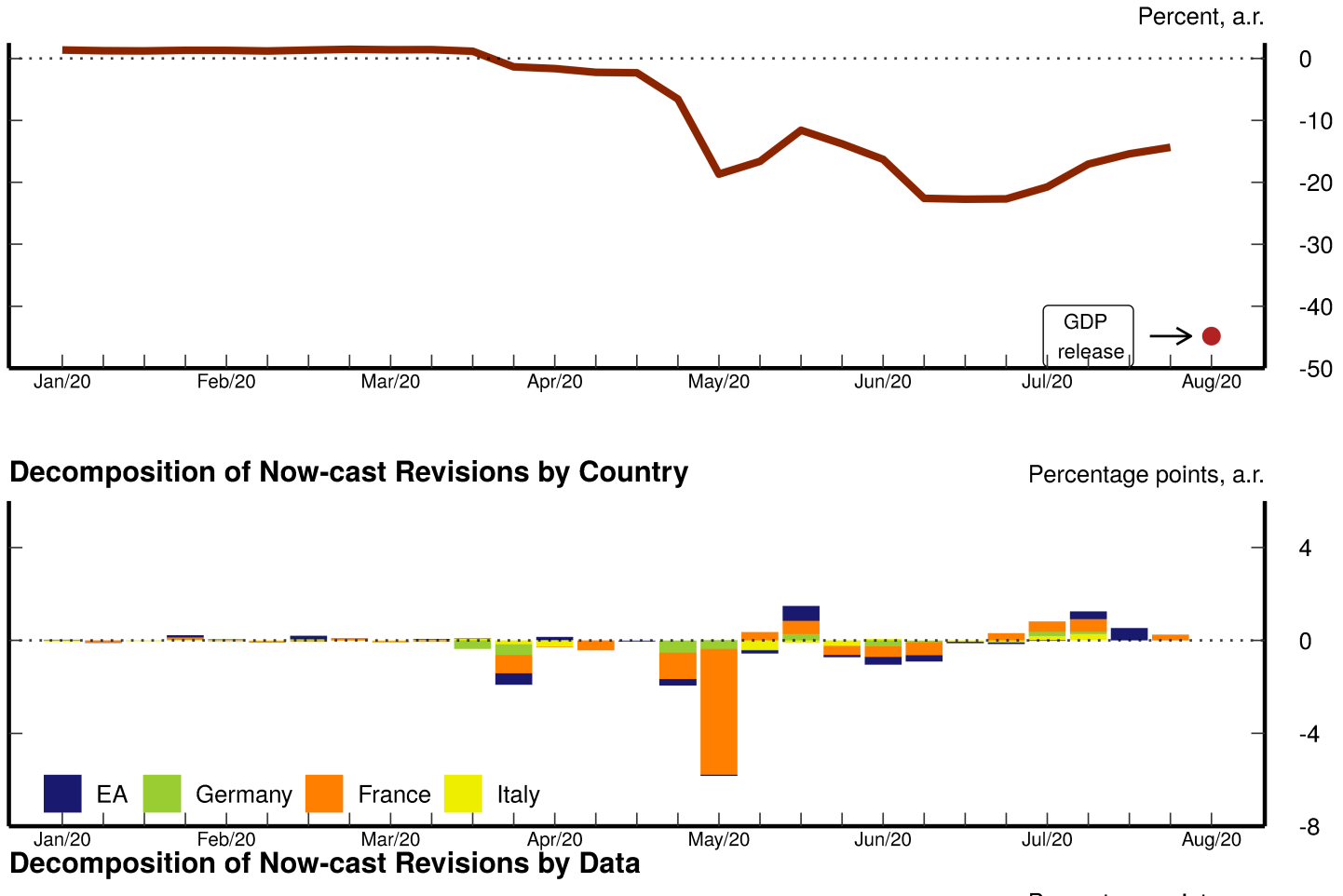

Decomposition of Now-cast Revisions by Data

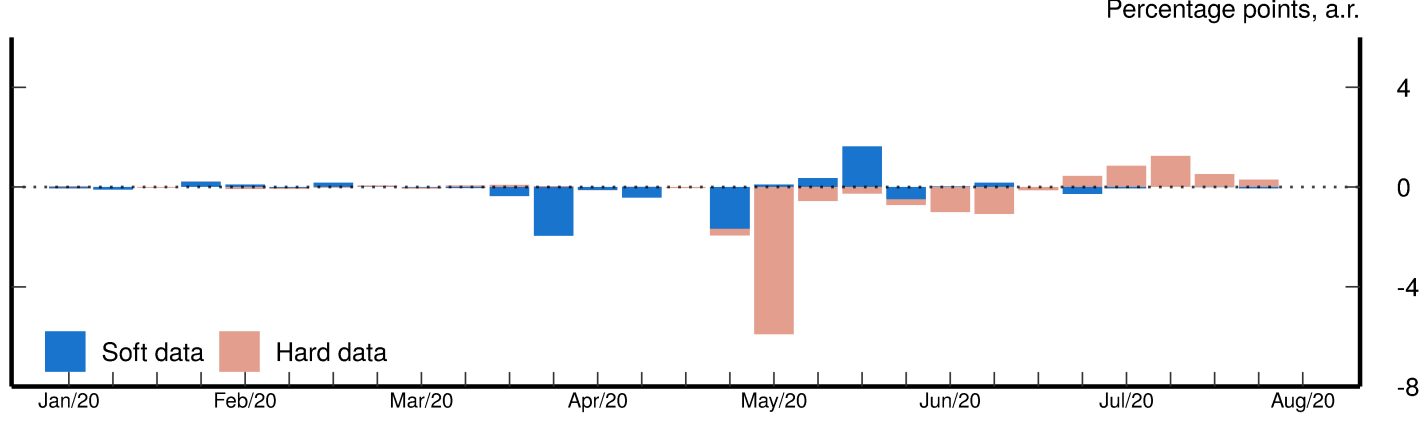

Note: Top panel presents weekly out-of-sample forecasts from our now-casting model. Red dot in top panel represents France quarterly GDP growth of 2020Q2. Middle panel presents the decomposition of the model forecast revisions by the country of origin of the data, whereas the bottom panel presents revisions by hard/soft data. Revisions due to estimation update are not shown. More details in Sections 3 and 4. 
Figure C.3 Italy GDP Growth During the 2020 COVID-19 Crisis

\section{Evolution of Estimates of Italy GDP Growth in 2020Q2}


Decomposition of Now-cast Revisions by Data

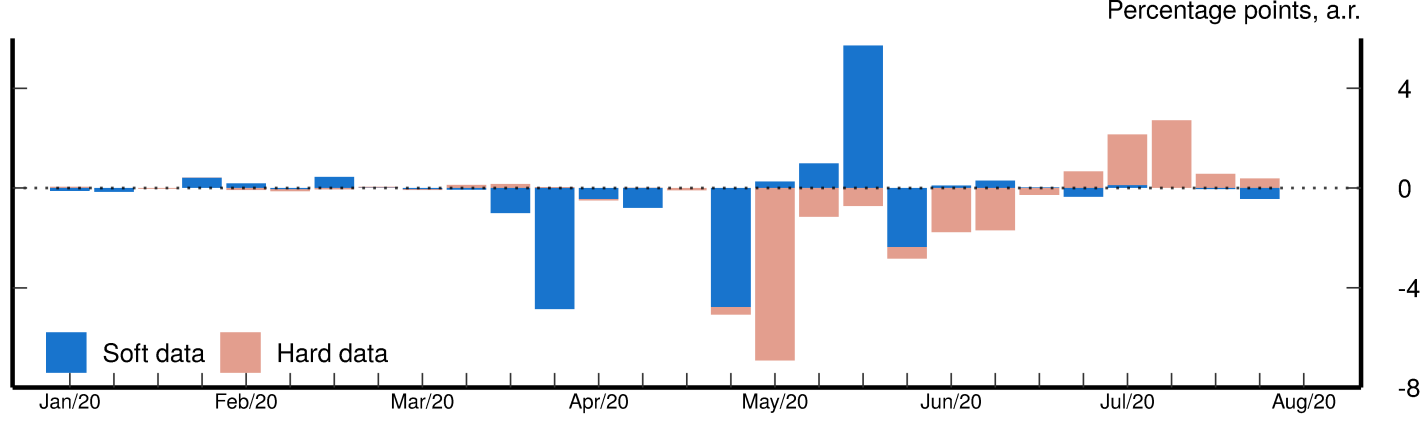

Note: Top panel presents weekly out-of-sample forecasts from our now-casting model. Red dot in top panel represents Italy quarterly GDP growth of 2020Q2. Middle panel presents the decomposition of the model forecast revisions by the country of origin of the data, whereas the bottom panel presents revisions by hard/soft data. Revisions due to estimation update are not shown. More details in Sections 3 and 目. 


\section{Supplementary Results}

Figure D.1 Empirical Distribution of Forecast Errors for Euro Area

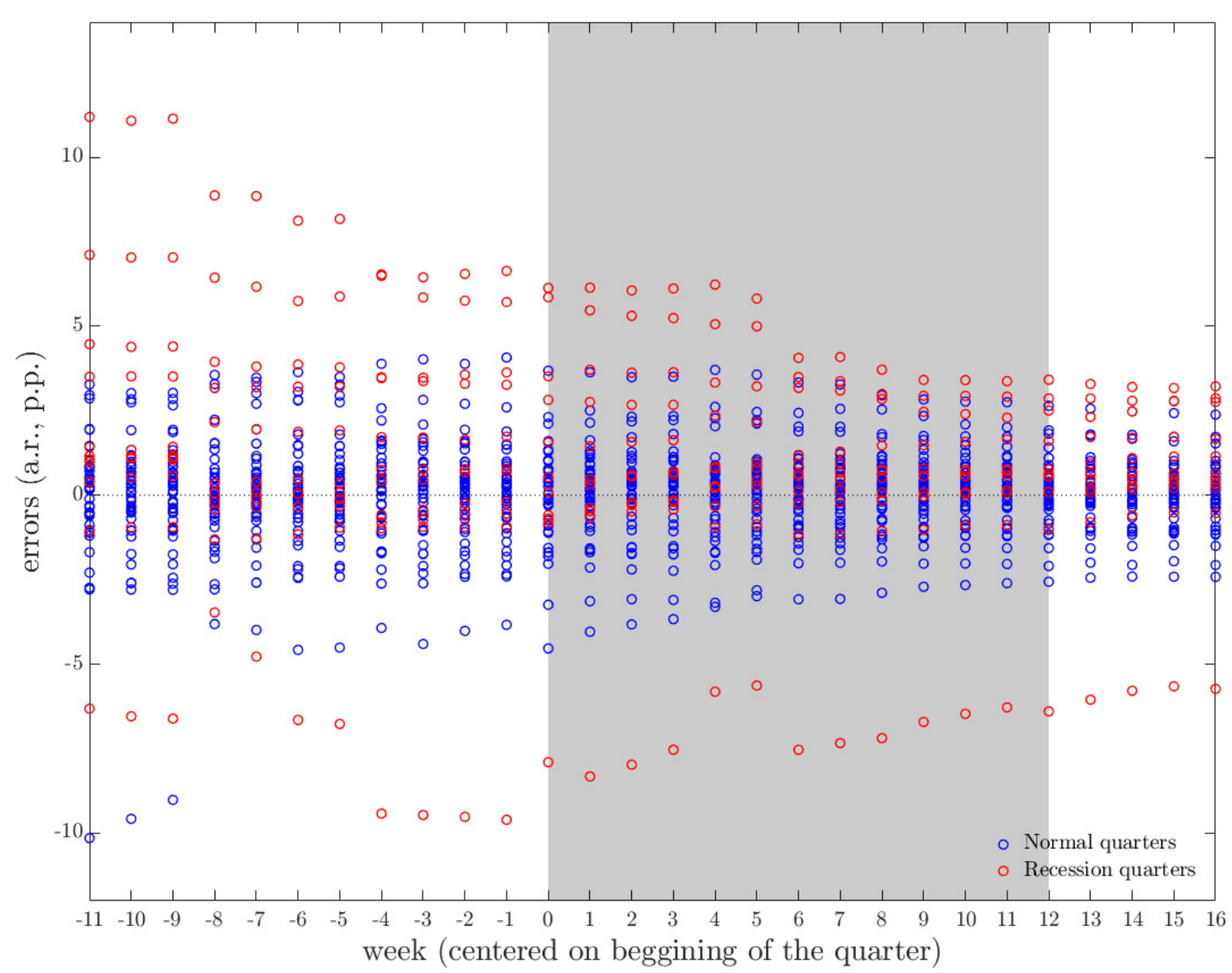

Note: Forecast errors are calculated under the out-of-sample exercise described in Section 3.3 using our now-casting model (Section 3.1). Red dots represent the errors when the forecasted quarter is in a recession period (from 2008Q2 to 2009Q2 and from 2011Q4 to 2013Q1), as defined by the Center for Economic and Policy Research (CEPR). Blue dots represent the errors when the forecasted quarter is of non-recession periods. The $x$-axis represents the weeks of the forecasted quarter, with negative numbers referencing the weeks before the start of the quarter. Shaded area represents the now-cast periods (current quarter forecast). White area before the shaded area represents forecast periods (one-quarter ahead forecast). White area after the shaded area represents back-cast periods (previous quarter forecast). 